\title{
Measurement and Modeling of Hydrogen Environment-Assisted Cracking in Monel K-500
}

\author{
RICHARD P. GANGLOFF, HUNG M. HA, JAMES T. BURNS, and JOHN R. SCULLY \\ Hydrogen environment-assisted cracking (HEAC) of Monel K-500 is quantified using \\ slow-rising stress intensity loading with electrical potential monitoring of small crack propa- \\ gation and elastoplastic $J$-integral analysis. For this loading, with concurrent crack tip plastic \\ strain and $\mathrm{H}$ accumulation, aged Monel K-500 is susceptible to intergranular HEAC in $\mathrm{NaCl}$ \\ solution when cathodically polarized at $-800 \mathrm{mV}_{\mathrm{SCE}}\left(E_{\mathrm{A}}, v s\right.$ saturated calomel) and lower. \\ Intergranular cracking is eliminated by reduced cathodic polarization more positive than \\ $-750 \mathrm{mV}_{\mathrm{SCE}}$. Crack tip diffusible $\mathrm{H}$ concentration rises, from near $0 \mathrm{wppm}$ at $E_{\mathrm{A}}$ of \\ $-765 \mathrm{mV}_{\mathrm{SCE}}$, with increasing cathodic polarization. This behavior is quantified by thermal \\ desorption spectroscopy and barnacle cell measurements of hydrogen solubility $v s$ overpotential \\ for planar electrodes, plus measured-local crevice potential, and $\mathrm{pH}$ scaled to the crack tip. \\ Using crack tip $\mathrm{H}$ concentration, excellent agreement is demonstrated between measurements \\ and decohesion-based model predictions of the $E_{\mathrm{A}}$ dependencies of threshold stress intensity \\ and Stage II growth rate. A critical level of cathodic polarization must be exceeded for HEAC to \\ occur in aged Monel K-500. The damaging-cathodic potential regime likely shifts more negative \\ for quasi-static loading or increasing metallurgical resistance to HEAC.
}

DOI: $10.1007 /$ s11661-014-2324-z

(C) The Minerals, Metals \& Materials Society and ASM International 2014

\section{INTRODUCTION}

MONEL K-500 (UNS N05500) is a precipitation hardened austenitic Ni-Cu-Al alloy that exhibits high strength, fracture toughness, and corrosion resistance in marine environments. However, this alloy is susceptible to environment-assisted cracking (EAC) when stressed in chloride solution with cathodic polarization. EAC was reported for threaded bolts in North Sea oil and gas platforms ${ }^{[1-9]}$ and submarine components ${ }^{[10,11]}$ where cathodic polarization protected steel coupled to Monel. Cracking in these environments was predominantly intergranular (IG) with limited transgranular (TG) morphologies reported. ${ }^{[12]}$ Field cracking is not unexpected given the susceptibility of precipitation hardened Ni-based superalloys to IG and TG EAC. ${ }^{[13-16]}$ However, the number of field failures is limited; and causal factors are not known among variations in Monel metallurgy, cathodic polarization, stress state, and interactions.

Literature establishes that hydrogen environmentassisted cracking (HEAC) is the likely mechanism for

RICHARD P. GANGLOFF and JOHN R. SCULLY, Professors, and JAMES T. BURNS, Research Assistant Professor, are with the Department of Materials Science and Engineering, Center for Electrochemical Science and Engineering, University of Virginia, Charlottesville, VA 22904. Contact e-mail: rpg7y@ Virginia.edu. HUNG M. HA, formerly Research Scientist with the Department of Materials Science and Engineering, Center for Electrochemical Science and Engineering, University of Virginia, is now Post-Doctoral Research Fellow with the Department of Materials Engineering, University of British Columbia, Vancouver, BC V6T 1Z4, Canada.

Manuscript submitted July 16, 2013.

Article published online May 17, 2014
EAC in Monel K-500 in marine environments that include cathodic polarization. Nickel is susceptible to IG HEAC in electrolytes, particularly under cathodic polarization and in acidic solutions which promote atomic hydrogen $(\mathrm{H})$ production, ${ }^{[16]}$ as well as in low pressure $\mathrm{H}_{2}{ }^{[17]}$ Precharged $\mathrm{H}$ caused IG internal-Hassisted cracking (IHAC) in $\mathrm{Ni}^{[18,19]} \mathrm{Ni}-\mathrm{Cu}$ solid solutions, ${ }^{[20]}$ and $\mathrm{Fe}$ and $\mathrm{Ni}$ superalloys. ${ }^{[21,22]}$ Ductile microvoid cracking in Monel K-500 transitioned to IG cracking due to precharged $\mathrm{H}$ followed by static loading in moist air [at $448 \mathrm{~K}$ to $533 \mathrm{~K}\left(175{ }^{\circ} \mathrm{C}\right.$ to $\left.260{ }^{\circ} \mathrm{C}\right)$ ], ${ }^{[23]}$ or by slow-rate rising displacement deformation in either air at $298 \mathrm{~K}\left(25^{\circ} \mathrm{C}\right)^{[24]}$ or $\mathrm{NaCl}$ solution with cathodic polarization. ${ }^{[25]}$ The extent of IG IHAC increased with increasing concentration of precharged $\mathrm{H},{ }^{[24]}$ consistent with well-known IHAC behavior of steels. ${ }^{[13]}$ Low strength solid solution Monel Alloy 400 was susceptible to IG and TG IHAC. ${ }^{[26,27]}$

The severity of EAC in Monel K-500 in chloride solution increases with increasing cathodic polarization, ${ }^{[2,25,28]}$ which increases the overpotential for $\mathrm{H}$ production from water reduction, thus increasing the amount of $\mathrm{H}^{\left[{ }^{[29]}\right.}$ Absorbed $\mathrm{H}$ migrates to the highly stressed-localized crack tip fracture process zone (FPZ) where damage nucleates. ${ }^{[13]}$ HEAC in a precracked specimen is often dominated by $\mathrm{H}$ production and uptake on crack tip surfaces due to the short diffusion distance $(\sim 1 \mu \mathrm{m})$ to highly stressed FPZ damage sites. ${ }^{[13]}$ However, long exposure time and reduced overpotential for $\mathrm{H}$ production at the crack tip ${ }^{[29]}$ suggest that a boldsurface source of $\mathrm{H}$ must be considered for HEAC in $\mathrm{Ni}$ superalloys. A study of IN718 showed that the threshold stress intensity factor $\left(K_{\mathrm{TH}}\right)$ for HEAC in high pressure 
$\mathrm{H}_{2}$ or acidified chloride decreased as a unique function of increasing concentration of $\mathrm{H}$ produced at the crack tip. ${ }^{[14]}$ The HEAC crack path transitioned from slip band-based TG to IG with increasing $\mathrm{H}$ content. ${ }^{[14]}$ Such a correlation has not been reported for Monel $\mathrm{K}-500$ in aqueous chloride solution. Moreover, except for limited reports of apparent threshold properties, ${ }^{[28,30]}$ fracture mechanics-based characterization of EAC is lacking for Monel K-500. Most studies used the slow strain rate method applied to a smooth- or bluntnotch specimen immersed in chloride solution to characterize EAC and isolate causal factors. ${ }^{[2-6,10,24,25,31,32]}$ Metallurgical candidates include cold work prior to aging resulting in high hardness, alloy composition variation, grain boundary carbide/graphite, segregated impurities such as $\mathrm{S}, \mathrm{P}$ or $\mathrm{Se},{ }^{[18]}$ and grain boundary misorientation. ${ }^{[33]}$ Investigation of the metallurgical factors which govern HEAC is outside the scope of the present study, but the approach reported here will inform such future work.

Proposed mechanisms for hydrogen cracking include: hydrogen-enhanced decohesion (HEDE), hydrogenenhanced localized plasticity (HELP), and adsorptioninduced dislocation emission (AIDE).$^{[13,34]}$ Others argue for cracking through or along a hydride $\left((\mathrm{Ni}, \mathrm{Cu})_{x} \mathrm{H}\right)$, which can form in Monel K-500 at $298 \mathrm{~K}\left(25^{\circ} \mathrm{C}\right)$ and $\mathrm{H}$ contents of 10 to 25 parts-per-million by weight (wppm). ${ }^{[20,35-37]}$ The contributions of these mechanisms to HEAC are controversial, ${ }^{[13,34]}$ but recent transmission electron microscopy suggests interactive HEDE and HELP. ${ }^{[38]}$ Boundary decohesion is enabled by local stress elevation from $\mathrm{H}$-sensitive strain hardening, plus $\mathrm{H}$ enrichment due to slip band or substructure trapping of $\mathrm{H}$ and $\mathrm{H}$ transport from dislocation plasticity. Hydrogen also promotes increased slip band localization in the Ni matrix,${ }^{[39]}$ which could elevate micro-scale tensile stresses for IG decohesion (or favor TG slip band cracking). Electron microscopy did not evidence either hydride phase, cracking from such precipitates, ${ }^{[20]}$ or super-abundant vacancy stabilization by $\mathrm{H}^{\left[{ }^{[0]}\right.}$

It is critical to develop mechanism-based models, which predict quantitative HEAC kinetics for Monel K-500 in chloride solution, focusing on the effect of cathodic polarization and crack tip $\mathrm{H}$ concentration. The HEDE mechanism provides a basis for models which predict $K_{\mathrm{TH}}$, as well as the upper-bound Stage II crack growth rate $\left(\mathrm{d} a / \mathrm{d} t_{\mathrm{II}}\right)$ controlled by the rate limiting step in the production and FPZ diffusion of $\mathrm{H}^{[13]}$ The $K_{\mathrm{TH}}$ model developed by Gerberich et al. ${ }^{[41-}$ ${ }^{43]}$ successfully predicted the applied potential and $\mathrm{H}_{2}$ pressure dependencies of $K_{\mathrm{TH}}$ in high strength steels:

$$
K_{\mathrm{TH}}=\frac{1}{\beta^{\prime}} \exp \frac{\left(k_{\mathrm{IG}}-\alpha C_{\mathrm{H} \sigma}\right)^{2}}{\alpha^{\prime \prime} \sigma_{\mathrm{YS}}},
$$

where $\beta^{\prime}\left((\mathrm{MPa} \sqrt{\mathrm{m}})^{-1}\right)$ and $\alpha^{\prime \prime}(\mathrm{MPa} \mathrm{m})$ are constants in a dislocation-shielding model of crack tip elastic stress, $C_{\mathrm{H} \sigma}$ (atom fraction $\mathrm{H}$ ) is the crack tip stress-enhanced diffusible $\mathrm{H}$ concentration adjacent to the crack path in the FPZ, and $\alpha(\mathrm{MPa} \sqrt{\mathrm{m}}$ per atom fraction $\mathrm{H})$ is a weighting factor which defines lowering of the Griffith toughness $\left(k_{\mathrm{IG}}, \mathrm{MPa} \sqrt{\mathrm{m}}\right)$ per unit $\mathrm{H}$ concentration. This model captures the interplay between crack tip plasticity and stress-based decohesion. ${ }^{[44]}$

For a wide range of high strength alloy-environment combinations that crack by HEAC, $\mathrm{H}$ diffusion in the crack tip FPZ limits $\mathrm{d} a / \mathrm{d} t_{\mathrm{II}},{ }^{[45]}$ provided that surface reaction rate is rapid. Modeling of $\mathrm{H}$ diffusion ahead of a discontinuously propagating crack yielded ${ }^{[42,46]}$ :

$$
\left(\frac{\mathrm{d} a}{\mathrm{~d} t}\right)_{\mathrm{II}}=\frac{4 D_{\mathrm{H}}}{x_{\text {crit }}}\left\{\operatorname{erf}^{-1}\left(1-\frac{C_{\mathrm{H} \sigma-\mathrm{crit}}}{C_{\mathrm{H} \sigma}}\right)\right\}^{2},
$$

where $D_{\mathrm{H}}$ is the reversible-trap affected diffusivity of $\mathrm{H}$, $x_{\text {crit }}$ is the critical distance ahead of the crack tip where $\mathrm{H}$ cracking nucleates for a discontinuous crack advance increment, and $C_{\mathrm{H} \sigma \text {-crit }}$ is the critical local concentration of $\mathrm{H}$ necessary for $\mathrm{H}$ cracking by decohesion at $x_{\text {crit }}$. $C_{\mathrm{H} \sigma \text {-crit }}$ is a property of the interface and depends on local tensile stress via a failure criterion. $C_{\mathrm{H} \sigma \text {-crit }}$ is related to the amount of local $\mathrm{H}\left(C_{\mathrm{H} \sigma}\right)$ required to produce a local lowering of the intrinsic Griffith toughness, as qualitatively captured by the $\alpha$ term in Eq. [1]. ${ }^{[22,46]} x_{\text {crit }}$ reflects the interaction of crack tip tensile stress and $\mathrm{H}$ concentration gradient, and is of order $1 \mu \mathrm{m}$ for high strength $\mathrm{Ti}, \mathrm{Fe}, \mathrm{Al}$, and Ni-based alloys ${ }^{[45]}$ suggesting damage localization at the maximum in the crack tip $\sigma_{\mathrm{H}}$ distribution $^{[47]}$ or $\mathrm{H}$-sensitive dislocation structure ${ }^{[38,44]} D_{\mathrm{H}}$ for $\mathrm{H}$ in aged Monel $\mathrm{K}-500$ at $298 \mathrm{~K}\left(25^{\circ} \mathrm{C}\right)$ was reported to be 5 to $6 \times 10^{-11} \mathrm{~cm}^{2} / \mathrm{s},{ }^{[48]} 1.5$ to $1.9 \times 10^{-10} \mathrm{~cm}^{2} / \mathrm{s}^{[24]}$ and $9 \times 10^{-11}$ to $4 \times 10^{-10} \mathrm{~cm}^{2} / \mathrm{s},{ }^{[29]}$ suggesting an upperbound $\mathrm{d} a / \mathrm{d} t_{\text {II }}$ from Eq. [2] of 20 to $160 \mathrm{~nm} / \mathrm{s}$. Equations [1] and [2] model cracking controlled by the interplay of crack tip stress and $\mathrm{H}$ to cause interface decohesion, independent of loading protocol. Lower levels of crack tip $\mathrm{H}$ uptake may increase the dependence of HEAC on plastic strain; the micromechanics must capture the loading format-history dependence of the crack tip strain field. ${ }^{[49]}$

$C_{\mathrm{H} \sigma}$ in Eqs. [1] and [2] is in equilibrium with the crack tip overpotential for $\mathrm{H}$ production, and is derived as follows. Diffusible $\mathrm{H}$ concentration, $C_{\mathrm{H}-\mathrm{Diff}}$, is the sum of the lattice $\mathrm{H}$ concentration $\left(C_{\mathrm{L}}\right)$ and reversibly trapped $\mathrm{H}$ concentration $\left(C_{\mathrm{RT}}\right)$, assuming a singlereversible trap site with $C_{\mathrm{RT}}$ in local equilibrium with $C_{\mathrm{L}}$ and described using Fermi-Dirac statistics. ${ }^{[50]}$ The lattice-interstitial $\mathrm{H}$ content is enhanced by the crack tip elastic stress field and a Fermi-Dirac distribution. ${ }^{[51]}$ These considerations yield crack tip stress-enhanced $C_{\mathrm{H}-\mathrm{Diff}}$, which is $C_{\mathrm{H} \sigma}$ in Eqs. [1] and [2]:

$$
\begin{array}{r}
C_{\mathrm{H} \sigma}=\left[C_{\mathrm{L}} \frac{\left(1-C_{\mathrm{L} \sigma}\right)}{\left(1-C_{\mathrm{L}}\right)} \exp \left(\frac{\sigma_{\mathrm{H}} V_{\mathrm{H}}}{\mathrm{RT}}\right)\right] \\
{\left[1+\frac{\left(1-C_{R T}\right)}{\left(1-C_{\mathrm{L}}\right)} \exp \left(\frac{E_{\mathrm{B}}}{\mathrm{RT}}\right)\right],}
\end{array}
$$

where $\sigma_{\mathrm{H}}$ is crack tip hydrostatic stress given by 3 to 20 times alloy yield strength $\left(\sigma_{\mathrm{YS}}\right),{ }^{[47]} \mathrm{V}_{\mathrm{H}}$ is the partial molar volume of $\mathrm{H}$ in the Ni lattice $\left(1.73 \mathrm{~cm}^{3} / \mathrm{mol} \mathrm{H}\right)$, $E_{\mathrm{B}}$ is the binding energy of $\mathrm{H}$ to the dominant-reversible trap site, $C_{\mathrm{L} \sigma}$ is the concentration of stress-enhanced lattice H, and RT has the usual meaning. Equation [3] is based on the assumptions that $\sigma_{\mathrm{H}}$ increases $C_{\mathrm{L}}$ due to 
lattice dilation, ${ }^{[51]}$ thus enhancing $C_{\mathrm{RT}}$ in equilibrium with $C_{\mathrm{L} \sigma}$, and that stress does not affect $E_{\mathrm{B}}$. Equation [3] neglects $H$ trapping at crack tip dislocation structure. ${ }^{[49,52,53]}$ Research on $\mathrm{H}$ uptake and diffusion in Monel K-500, ${ }^{[2]}$ extended in the present research, establishes the applied cathodic potential dependence of crack tip $C_{\mathrm{H} \text {-Diff }}$ necessary to implement the models in Eqs. [1] through [3]. ${ }^{[29]}$ This approach was applied to model HEAC in ultra-high strength steels. ${ }^{[42,54]}$

The objectives of this research are to: (1) enhance an accelerated fracture mechanics test method for HEAC in moderate strength alloys ${ }^{[42,55]}$ (2) quantitatively characterize the HEAC kinetics of aged Monel K-500 in aqueous chloride solution with cathodic polarization, (3) establish $C_{\mathrm{H} \sigma} v s$ applied cathodic potential for Monel $\mathrm{K}-500$, and (4) model the applied potential dependencies of $K_{\mathrm{TH}}$ and $\mathrm{d} a / \mathrm{d} t_{\mathrm{II}}$ based on crack tip $\mathrm{H}$ uptake using Eqs. [1] and [2]. Precracked specimens are loaded under slow-rising displacement, crack growth is monitored by a high precision direct current potential difference (dcPD) method, and the crack tip driving force is defined by an elastoplastic $J$-integral analysis which has not been broadly utilized to characterize HEAC. ${ }^{[56-58]}$

\section{EXPERIMENTAL PROCEDURE}

\section{A. Material and Specimen Design}

Hot finished and aged bar (15.9 mm diameter) of Monel K-500 was purchased from ATI Allvac with the vendor composition in Table I and mechanical properties in Table II. These properties were developed by hot working then age hardening: 16 hours at $866 \mathrm{~K}$ $\left(593{ }^{\circ} \mathrm{C}\right)$, cool at $14 \mathrm{~K} / \mathrm{h}\left(14^{\circ} \mathrm{C} / \mathrm{h}\right)$ to $755 \mathrm{~K}\left(482{ }^{\circ} \mathrm{C}\right)$, and air cool to ambient temperature. This heat treatment should result in coherent-spherical $\mathrm{Ni}_{3} \mathrm{Al}$ precipitate strengthened $\left(\gamma^{\prime}\right.$ phase of order $5 \mathrm{~nm}$ radius, 8 to 10 vol pet, and possibly with dissolved $\mathrm{Ti}, \mathrm{Cu}, \mathrm{Si}$, or $\mathrm{Mn}$ ) Ni-Cu solid solution austenite (face-centered cubic $\gamma$ phase). ${ }^{[59]}$ Ramberg-Osgood flow rule constants ${ }^{[60]}$ were determined for this lot of aged Monel K-500 using compression loading to 2 pet total strain: $\alpha=0.39$, $n=20, \quad E=185,700 \mathrm{MPa}$, and $\sigma_{\mathrm{o}}=\sigma_{\mathrm{YS}}(0.2 \mathrm{pct}$ offset $)=786 \mathrm{MPa}$, consistent with Table II.

Single edge micronotch tensile (SENT) specimens were machined with a width $(W)$ of $10.7 \mathrm{~mm}$ and thickness $(B)$ of $2.54 \mathrm{~mm} .^{[42]}$ The Mode I loading axis was parallel to the longitudinal direction $(L)$ of the rod, with crack growth in the radial $(R)$ direction. The notch was electrospark discharge machined to a depth of $200 \pm 10 \mu \mathrm{m}$ and mouth opening of $235 \pm 20 \mu \mathrm{m}$. The SENT specimen was fatigue cracked in moist air to a notch plus short-crack depth $\left(a_{\mathrm{o}}\right)$ of 850 to $1150 \mu \mathrm{m}$, with the maximum-elastic stress intensity factor $\left(K_{\max }\right)$ decreasing from 18 to $13 \mathrm{MPa} \sqrt{\mathrm{m}}$ at constant $R\left(K_{\min } /\right.$ $\left.K_{\max }\right)$ of 0.10 .

\section{B. Crack Length Measurement}

The dcPD method was used to measure crack length with a constant direct current of $4.000 \pm 0.005 \mathrm{~A}^{\text {[61] }}$ This procedure included current-polarity reversal to eliminate thermally induced voltages, crack potential difference normalization by a remote reference measurement, and active-normalized potential values averaged in groups of 50. ${ }^{[62]}$ The resolution in measured potential was $0.1 \mu \mathrm{V}$, which corresponds to a resolvable average crack extension, $\Delta \mathrm{a}$, of $0.5 \mu \mathrm{m}$. Each dcPD value was converted to crack length $(a)$ by Johnson's calibration equation using the measured potential associated with the notch depth as the adjustable constant, $V_{\mathrm{o}}$, in this equation. ${ }^{[63]}$ All crack lengths from dcPD values were linearly corrected using the final optically measured crack length, which was averaged at five locations across the crack front. Predicted and measured crack lengths typically differed by less than 5 pct prior to linear correction.

To calculate crack growth rate $(\mathrm{d} a / \mathrm{d} t)$ at a given time $(t)$, a 2 nd order polynomial was fit to $a-t$ data over 7 data points. The slope of the tangent at the mid-point was $\mathrm{d} a / \mathrm{d} t$ and this process was repeated to obtain $\mathrm{d} a / \mathrm{d} t$ at every $a-t$ value. The $\mathrm{d} a / \mathrm{d} t$ was recorded for a crack advance increment, which exceeded $5 \mu \mathrm{m}$ or for a time interval of 50,000 seconds if less than $5 \mu \mathrm{m}$ of growth occurred. High resolution measurement of $\mathrm{d} a / \mathrm{d} t$ was challenged by two issues unique to this alloy strength and environment: (a) large scale ligament plasticity, which contributes to dcPD increase due to plasticitybased resistivity increase and tip blunting, and (b) crack surface electrical contact which decreases during crack opening. These issues resulted in a dcPD measurement resolution limit of $\mathrm{d} a / \mathrm{d} t$ between 0.2 and $1 \mathrm{~nm} / \mathrm{s}$ for Monel K-500, as detailed in Section III.

\section{Fracture Mechanics Analysis}

Crack growth rate data were analyzed using elastic $K$ and total stress intensity $\left(K_{\mathrm{J}}\right)$, which includes the effect

Table I. Chemical Composition of Monel K-500 (Weight Percent)

\begin{tabular}{lcccccccr}
\hline $\mathrm{Ni}$ & $\mathrm{Cu}$ & $\mathrm{Fe}$ & $\mathrm{C}$ & $\mathrm{Mn}$ & $\mathrm{Al}$ & $\mathrm{Ti}$ & $\mathrm{P}$ & $\mathrm{S}$ \\
\hline 66.12 & 28.57 & 0.80 & 0.166 & 0.81 & 2.89 & 0.45 & 0.015 \\
\hline
\end{tabular}

$\mathrm{Si}=0.08 ; \mathrm{Cr}=0.04 ; \mathrm{Zr}=0.03 ; \mathrm{Nb}, \mathrm{Ta}, \mathrm{W}, \mathrm{V}<0.01 ; \mathrm{Bi}, \mathrm{Pb}, \mathrm{Ag}, \mathrm{Sn}<0.0005$ wt pet.

Table II. Mechanical Properties of Monel K-500 (aged)

\begin{tabular}{lccccc}
\hline HRC & $\sigma_{\mathrm{YS}}(\mathrm{MPa})$ & $\sigma_{\mathrm{UTS}}(\mathrm{MPa})$ & Reduction in Area $(\mathrm{pct})$ & $E(\mathrm{GPa})$ & $K_{\mathrm{IC}}(\mathrm{MPa} \sqrt{\mathrm{m}})$ \\
\hline 31 & 773 & 1169 & 49.7 & $183.9^{[102]}$ & 198 to $340^{[28,30,73]}$ \\
\hline
\end{tabular}


of specimen plasticity from a $J$-integral analysis. Clevis gripping allowed free rotation of the SENT specimen to comply with the boundary condition for the elastic $K$ solution using physical crack length, $a .^{[64]} K_{\mathrm{J}}$ was determined using analytical solutions for a stationary crack in a material, which deforms according to the Ramberg-Osgood flow rule ${ }^{[60]}$ :

$$
K_{\mathrm{J}}=\sqrt{\left(J_{\text {Elastic }}+J_{\text {Plastic }}\right) \mathrm{E}^{\prime}}=\sqrt{\left(\frac{K^{2}}{E^{\prime}}+J_{\text {Plastic }}\right) \mathrm{E}^{\prime}},
$$

where $\mathrm{E}^{\prime}$ is measured $E$ for plane stress and $E /\left(1-v^{2}\right)$ for plane strain and $v$ is Poisson's ratio. In Eq. [4] elastic $K$ is based on effective crack length defined as physical crack length plus plane strain plastic zone correction $^{[60]}$ :

$$
a_{\mathrm{eff}}=a+\frac{1}{1+\left(\frac{P}{P_{\mathrm{O}}}\right)^{2}} \frac{1}{6 \pi}\left(\frac{n-1}{n+1}\right)\left(\frac{K_{\text {elastic }}}{\sigma_{\mathrm{o}}}\right)^{2} .
$$

The plastic contribution to $J$ in Eq. [4] is ${ }^{[65]}$ :

$$
J_{\text {Plastic }}=\frac{\alpha \sigma_{\mathrm{o}}^{2}}{E} a \frac{(W-a)}{W} h_{1}(n, a / W)\left(\frac{P}{P_{\mathrm{o}}}\right)^{n+1},
$$

where $\alpha, \sigma_{\mathrm{o}}$, and $n$ are constants in the RambergOsgood equation, $E$ is $\sigma_{\mathrm{o}} / \epsilon_{\mathrm{o}}, a$ is crack length, $W$ is SENT width, $h_{1}$ is a hardening and geometry dependent scaling function, $P$ is load, and $P_{\mathrm{o}}$ is the limit load for net section plastic deformation given by ${ }^{[60]}$ :

$$
P_{\mathrm{o}}=\beta\left(\sqrt{1+\left(\frac{a}{W-a}\right)^{2}}-\left(\frac{a}{W-a}\right)\right)(W-a) B \sigma_{\mathrm{o}}
$$

where $B$ is thickness and $\beta$ equals 1.455 for plane strain. The $h_{1}$ function for the rotating SENT specimen ( $n$ of 20 ) was defined by a sixth-order polynomial fit to discrete values and negative $h_{1}$ were precluded. ${ }^{[65]}$ Stress state dependent terms in Eqs. [4] through [7] were assumed to be plane strain values, justified by three-dimensional finite element analyses ${ }^{[66,67]}$ and the flat Mode I appearance of all EAC surfaces for Monel K-500.

\section{Electrochemical Control and Loading Conditions}

The precracked SENT specimen was loaded in a $340 \mathrm{~mL}$ cylindrical Plexiglas cell containing non-deaerated $0.6 \mathrm{M}$ (3.5 wt pct) $\mathrm{NaCl}$ circulated from a $4 \mathrm{~L}$ reservoir at $20 \mathrm{~mL} / \mathrm{min}$ and room temperature. Solution was not buffered and periodic measurements confirmed bulk $\mathrm{pH}$ of 6 to 7 for the duration of each experiment. Only the cracked section of the specimen was exposed to solution, precluding galvanic coupling with the grips. The SENT specimen (working electrode) was grounded through the test machine, while the potentiostat operated in floating mode to avoid a ground loop. Experiments were run in potentiostatic control with applied potential $\left(E_{\mathrm{A}}\right)$ from -1100 to $-700 \mathrm{mV}_{\mathrm{SCE}}$, compared to an open circuit potential of -200 to $-250 \mathrm{mV}_{\mathrm{SCE}}{ }^{[28]}$ referenced to saturated calomel (SCE). The platinum-coated
Nb-mesh counter electrode surrounded the specimen and the SCE was located in the cell. After immersion in $\mathrm{NaCl}$ solution, the specimen was cyclically loaded for 500 cycles at $1 \mathrm{~Hz}$ and the final precrack stress intensity range to assure that the aqueous environment contacted the crack tip.

The precracked SENT specimen was loaded under slow actuator displacement control in a servo-hydraulic machine. Displacement rate was varied in real time by computer control to provide a constant rate of elastic $K$ increase, $\mathrm{d} K / \mathrm{d} t$, during crack growth. A loading protocol was programed to optimize test time: $\mathrm{d} K / \mathrm{d} t=$ $5.5 \mathrm{MPa} \sqrt{\mathrm{m}} / \mathrm{h}$ for elastic $K$ up to $5.5 \mathrm{MPa} \sqrt{\mathrm{m}}$ where SCC is improbable, $\mathrm{d} K / \mathrm{d} t=0.33 \mathrm{MPa} \sqrt{\mathrm{m}} / \mathrm{h}$ for $K$ from 5.5 to $43.9 \mathrm{MPa} \sqrt{\mathrm{m}}$, and $\mathrm{d} K / \mathrm{d} t=1.1 \mathrm{MPa} \sqrt{\mathrm{m}} / \mathrm{h}$ for $K$ above $43.9 \mathrm{MPa} \sqrt{\mathrm{m}}$. These rates were selected based on experience with HEAC in steel ${ }^{[42]}$ and IN718 ${ }^{[14]}$; the effect of $\mathrm{d} K / \mathrm{d} t$ was not measured for Monel K-500 in $\mathrm{NaCl}$ solution. A single test was performed in low humidity $\mathrm{N}_{2}(<10$ pet $\mathrm{RH})$ at a $\mathrm{d} K / \mathrm{d} t$ of $1 \mathrm{MPa} \sqrt{\mathrm{m}} / \mathrm{h}$.

\section{E. Occluded Crevice Electrochemistry and Local Hydrogen Concentration}

Modeling of HEAC using Eqs. [1] through [3] requires determination of a microstructure-specific $\mathrm{H}$ uptake relationship, stated as $C_{\mathrm{H} \text {-Diff }} v s$ the overpotential for $\mathrm{H}$ production $\left(\eta_{\mathrm{H}}\right)$, coupled with knowledge of crack tip $\mathrm{pH}$ and potential to yield crack tip $\eta_{\mathrm{H}}$; all vs $E_{\mathrm{A} .}{ }^{[54]}$ Crack-tip $\mathrm{pH}$ and potential were established for Monel K-500 using the artificial crevice geometry shown in Figure 1, coupled with the scaling-law approach to relate crevice and crack geometry difference. ${ }^{[68-70]}$ The cell consisted of: (a) an acrylic bottom plate with six disk specimens embedded and shorted to form a continuous working electrode (WE), (b) a plastic shim to create the crevice gap $(G)$, and (c) an acrylic top plate to form the crevice and hold micro-reference electrodes (REs) for local potential measurement. Monel K-500 specimens (surface area $\sim 3 \mathrm{~cm}^{2}$ ) were polished through 600 grit, degreased with ethanol, and mounted (Figure 1) at a distance $(x)$ of $1,3,5,7$, and $9 \mathrm{~cm}$ from the crevice mouth to create $x^{2} / G=10,90,250,490$ and $810 \mathrm{~cm}$. Only $x$ was varied for fixed $G$ of $1 \mathrm{~mm}$. Crevice potential

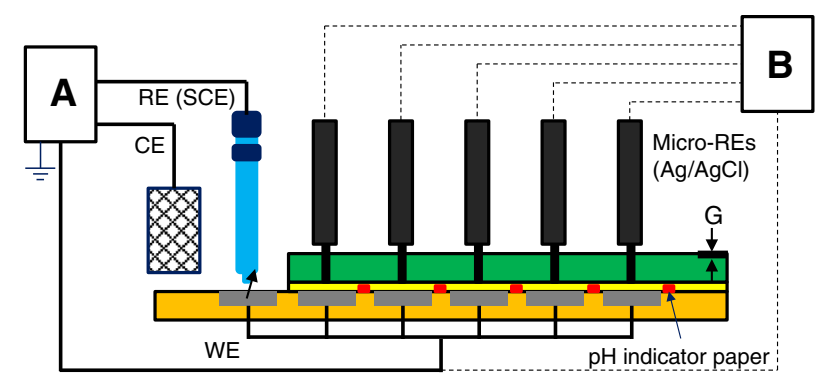

Fig. 1-(Color online) The artificial crevice electrochemical cell, where $A$ is a potentiostat, $\mathrm{CE}$ is a counter electrode, and $B$ is a multimeter to measure potential of 6-shorted alloy working electrodes (WE) in a crevice of opening-gap $(G)$. Standard and micro-reference electrodes (RE) measured potential and indicator paper measured local $\mathrm{pH}$. 
was correlated with $x^{2} / G$ because this parameter captures the geometric condition for equal-local potential in a crevice or crack. ${ }^{[54]}$ Local potential was measured using a $\mathrm{Ag} / \mathrm{AgCl}$ micro-reference electrode ${ }^{[54,71]}$ calibrated vs a SCE. Local $\mathrm{pH}$ was measured using $\mathrm{pH}$ indicator paper. Electrolyte outside the crevice mouth was $0.6 \mathrm{M} \mathrm{NaCl}$ ( $\mathrm{pH}=6$ to 7 ) and the cell was open to air.

The $\mathrm{H}$ uptake relationship for Monel K-500, $C_{\mathrm{H}-\mathrm{Diff}}$ vs $E_{\mathrm{A}}$, was determined using either thermal desorption spectroscopy (TDS) or barnacle cell (BC) extraction of $\mathrm{H}$ using planar electrodes. Electrodes were $\mathrm{H}$ precharged for 10 days in $0.6 \mathrm{M} \mathrm{NaOH}$ maintained at $\mathrm{pH}$ 8 with $\mathrm{NaOH}$ addition. It is assumed that $\mathrm{H}$ uptake in the Monel K-500 crack is insensitive to local $\mathrm{pH}$, at constant $\eta_{\mathrm{H}}$ for the expected $\mathrm{pH}$ levels above 6 , as found elsewhere. $^{[54]}$ This data base was used to determine $C_{\text {H-Diff }}$ at each local potential for the value of $x^{2} / G$ pertinent to crack opening shape in Monel K-500.

\section{RESULTS}

\section{A. Crack Tip Hydrogen Uptake}

Crack-tip $\mathrm{pH}$ and local potential, and associated $\mathrm{H}$ uptake, were established as a function of cathodic potential for Monel K-500.* Figure 2 shows local

*It is assumed that crack tip potential and $\mathrm{pH}$ are not affected by heat-to-heat differences in Monel K-500. As such, a lot of Monel K-500 was investigated, which was used in a prior study ${ }^{[29]}$ : Special Metals; Ni-30.2Cu-1.66Fe-0.17C-0.58Mn-2.69Al-0.61Ti-0.007P- $<10 \mathrm{ppm}$ $\mathrm{S}$ (by wt pct); aged at $866 \mathrm{~K}\left(593{ }^{\circ} \mathrm{C}\right)$ (16 hours), $811 \mathrm{~K}\left(538{ }^{\circ} \mathrm{C}\right)$ (6 hours), $755 \mathrm{~K}\left(482{ }^{\circ} \mathrm{C}\right)(8$ hours $)$, air cooled; $\sigma_{\mathrm{YS}}=783 \mathrm{MPa}$, $\sigma_{\mathrm{UTS}}=1146 \mathrm{MPa}$, and $\mathrm{RA}=48$ pct. potential measured at different distances into the artificial crevice ( $x$, for $G=1 \mathrm{~mm}$ ) at external- $E_{\mathrm{A}}$ of -600 to $-1000 \mathrm{mV}_{\mathrm{SCE}}$ for exposure in bulk $0.6 \mathrm{M} \mathrm{NaCl}$ at pH 6 to 7. In all cases a positive-potential gradient was established inside the crevice after external potential was applied. Local potential increased, due to IR drop and high current density, as $x$ increased, and this potential gradient decreased with time due to decreased current density. No significant $\mathrm{pH}$ difference was observed as a function of $x^{2} / G$ inside the crevice. However, $\mathrm{pH}$ increased with more cathodic $E_{\mathrm{A}}$ at 300 seconds exposure, and with increasing exposure time. Crevice $\mathrm{pH}$ measurements after 300 seconds exposure established this association: crevice $\mathrm{pH} 10$ at $E_{\mathrm{A}}$ of $-1000 \mathrm{mV}_{\mathrm{SCE}}$, pH 8 at $-900 \mathrm{mV}_{\mathrm{SCE}}, \mathrm{pH} 8$ at $-800 \mathrm{mV}_{\mathrm{SCE}}, \mathrm{pH} 7.5$ at $-700 \mathrm{mV}_{\mathrm{SCE}}$, and $\mathrm{pH} 7$ at $-600 \mathrm{mV}_{\mathrm{SCE}}$. The sharp change in crevice potential at 10 seconds $\left(-900 \mathrm{mV}_{\mathrm{SCE}}\right)$ and at 5 hours $\left(-1000 \mathrm{mV}_{\mathrm{SCE}}\right)$ are likely experimental anomalies.

The distribution of hydrogen overpotential inside the Monel K-500 artificial crevice was calculated from local $\mathrm{pH}$ and potential (Figure 2) for exposure in bulk $0.6 \mathrm{M}$ $\mathrm{NaCl}$ at $\mathrm{pH} 6$ to 7 . Results are shown in Figure 3 as a function of $E_{\mathrm{A}}$ after 300 seconds and 10 hours exposures. At $E_{\mathrm{A}}$ of -600 and $-700 \mathrm{mV}_{\mathrm{SCE}}, \eta_{\mathrm{H}}$ was positive. At more negative-applied potentials $(-800$ and $\left.-900 \mathrm{mV}_{\mathrm{SCE}}\right), \eta_{\mathrm{H}}$ was negative at 300 seconds but rose above $0 \mathrm{mV}_{\mathrm{SCE}}$ for longer time (10 hours). At $-1000 \mathrm{mV}_{\mathrm{SCE}}$ and all time, $\eta_{\mathrm{H}}$ was always negative indicating net $\mathrm{H}$ production; overpotential was less negative with increasing distance from the crevice mouth and with time.

Total $\mathrm{H}$ content was measured for aged ATI Allvac Monel K-500 (Tables I and II) by both hot $923 \mathrm{~K}$ $\left(650{ }^{\circ} \mathrm{C}\right)$ extraction and hot extraction-calibrated TDS, along with $C_{\mathrm{H} \text {-diff }}$ from TDS and the BC methods, each $v s$
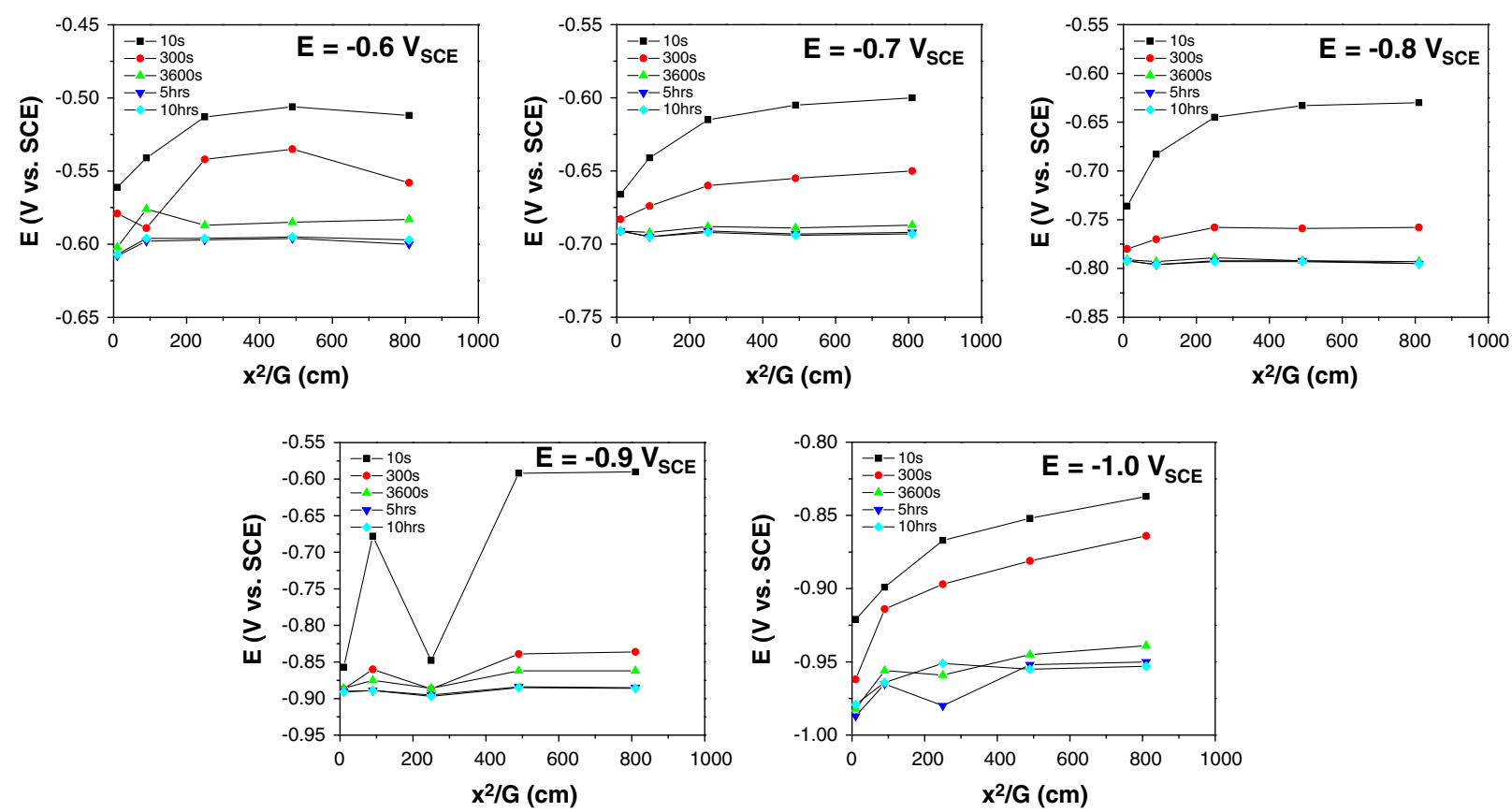

Fig. 2-(Color online) Local potential vs normalized position, $x$, along the artificial crevice with aged Monel K-500 (Special Metals lot, Footnote $\left.{ }^{*}\right)$, as a function of external-applied potential and exposure time in bulk $0.6 \mathrm{M} \mathrm{NaCl}$ solution. The crevice gap $(G)$ was $1 \mathrm{~mm}$. 

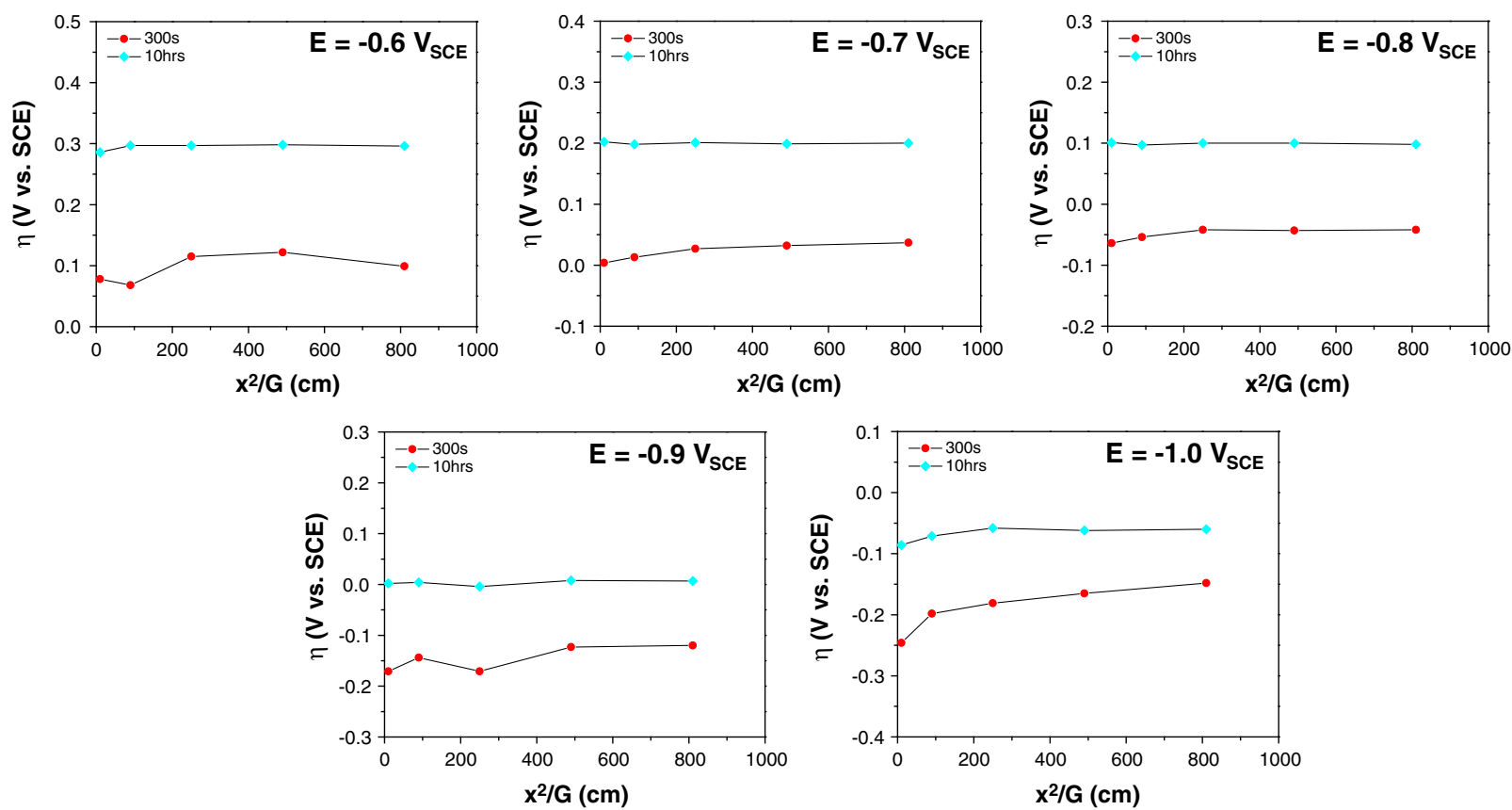

Fig. 3 - (Color online) Local-H overpotential vs normalized distance into the artificial crevice with aged Monel K-500 (Special Metals, Footnote *), as a function of $E_{\mathrm{A}}$ for exposures of $300 \mathrm{~s}$ and $10 \mathrm{~h}$ in bulk $0.6 \mathrm{M} \mathrm{NaCl}$, calculated using local potentials from Fig. 2. Solution pH at $x^{2} / G=0 \mathrm{was}$ 6 at all times and applied potentials. After $300 \mathrm{~s}, \mathrm{pH}$ values at all locations inside the crevice were 7, 7.5, 8, 8, and 10 when the $E_{\mathrm{A}}$ were $-0.6,-0.7$, $-0.8,-0.9$, and $-1.0 \mathrm{~V}_{\mathrm{SCE}}$, respectively. After $10 \mathrm{~h}, \mathrm{pH}$ at all locations inside the crevice was 11 at all $E_{\mathrm{A}}$.

$E_{\mathrm{A}}$ for a boldly exposed planar coupon. ${ }^{[29]}$ The results are shown in Figure 4, with the most reasonable H diffusivity for the $\mathrm{BC}$ data analysis being $1.3 \times 10^{-10} \mathrm{~cm}^{2} / \mathrm{s}$ for aged Monel K-500 at $298 \mathrm{~K}\left(25^{\circ} \mathrm{C}\right) \cdot{ }^{[29]}$ The TDS and BC methods yielded different $\mathrm{H}$ uptake relationships, as also observed for a different lot of Monel K-500. ${ }^{[29]}$ Regression through the TDS-based bold surface $C_{\mathrm{H}-\mathrm{Diff}} v s E_{\mathrm{A}}$ data in Figure $4(\square)$, converted to $\eta_{\mathrm{H}}$ for bulk $\mathrm{NaOH}$ solution $\mathrm{pH}$ 8, yielded:**

\footnotetext{
**A similar trend was measured using hot extraction-calibrated TDS for the lot of aged Monel K-500 represented in Footnote *, and Figs. 2 and 3, and exposed in $0.6 \mathrm{M}(\mathrm{pH}$ 8) $\mathrm{NaCl}$ solution: $C_{\mathrm{H}-\text { Diff }}(\mathrm{wppm})=-6.97-0.196 \eta_{\mathrm{H}}(\mathrm{mV})$. The concentration of diffusible $\mathrm{H}$ was substantially higher in this lot of Monel K-500 compared to the ATI Allvac lot represented by Eq. [8].
}

$$
C_{\mathrm{H}-\mathrm{Diff}}(\mathrm{wppm})=-3.37-0.085 \eta_{\mathrm{H}}(\mathrm{mV}) .
$$

The subsurface diffusible $\mathrm{H}$ concentration $\left(C_{\mathrm{H}-\text { Diff }}\right)$ at various $x^{2} / G$ within the crevice was determined as a function of $E_{\mathrm{A}}$ using crevice-position dependent $\eta_{\mathrm{H}}$ (from measured-local potential and $\mathrm{pH}$ at 300 seconds immersion, Figure 3) coupled with the bold surface $C_{\text {H-Diff }} v s \eta_{\mathrm{H}}$ relationship (Eq. [8]). Results are shown in Figure 5. Hydrogen uptake on the free surface $\left(x^{2} / G=0 \mathrm{~cm}\right)$ was computed using $\mathrm{pH} 6$ in the calculation of $\eta_{\mathrm{H}}$. The $C_{\mathrm{H}-\mathrm{Diff}}$ for this lot of aged Monel K-500 (ATI Allvac; Tables I and II), prior to $\mathrm{H}$ charging, was below the resolution of the TDS method.

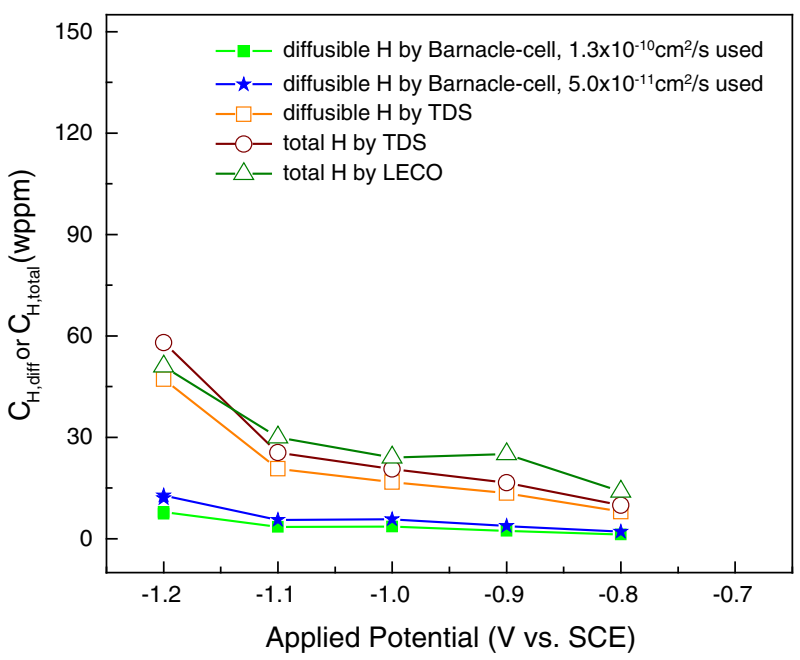

Fig. 4 -(Color online) Dissolved total and diffusible $\mathrm{H}$ concentrations measured $v s E_{\mathrm{A}}$ for aged Monel K-500 (ATI Allvac, Table I) planar electrodes immersed in $0.6 \mathrm{M} \mathrm{NaCl}(\mathrm{pH} 8$ with $\mathrm{NaOH}$ addition). Barnacle Cell and hot extraction (LECO)-calibrated TDS methods were used, as detailed elsewhere. ${ }^{[29]}$

A typical SENT crack grows from 1.3 to $3.2 \mathrm{~mm}$ ( $a=x$, including the $0.2 \mathrm{~mm}$ deep notch). The opening displacement $\left(G\right.$ in $\left.x^{2} / G\right)$ is approximated by the average of the elastoplastic crack tip opening displacement (CTOD) and elastic crack opening at the notch mouth. ${ }^{[00]}$ This average opening varies from 14 to $33 \mu \mathrm{m}$ for this crack extension interval at a typical $K$ of $40 \mathrm{MPa} \sqrt{\mathrm{m}}$. The associated $x^{2} / G$ rises from 9 to $27 \mathrm{~cm}$. For $1.3 \mathrm{~mm}<a<3.2 \mathrm{~mm}$, a twofold fall in $K$ 


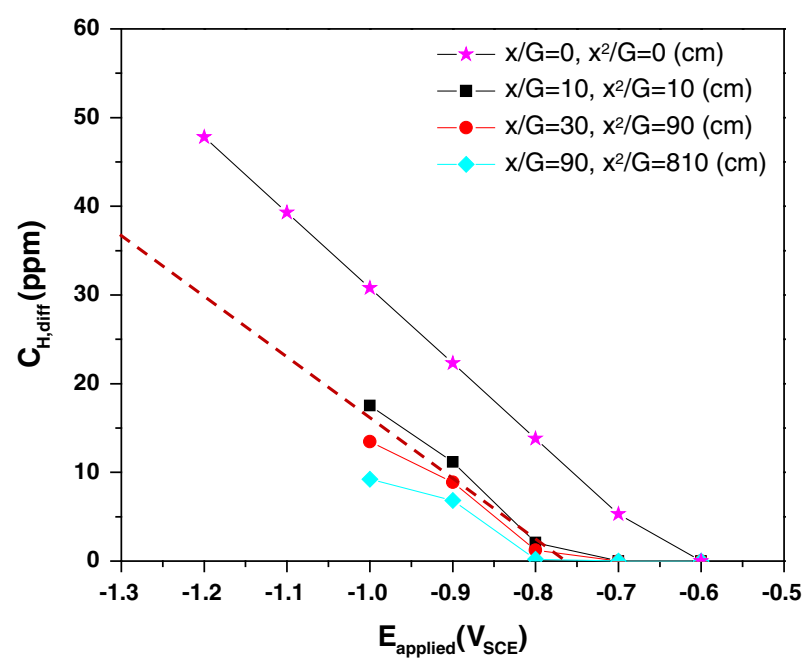

Fig. 5-(Color online) The effect of applied-external potential on diffusible $\mathrm{H}$ concentration produced at various locations within an artificial crevice for aged Monel K-500 (ATI Allvac, Table I), immersed in $0.6 \mathrm{M} \mathrm{NaCl}$ solution for $300 \mathrm{~s}$. After $300 \mathrm{~s}$, pH at $x^{2} / G=0$ was 6 at all $E_{\mathrm{A}}$; at all other locations, $\mathrm{pH}$ values were $7,7.5,8,8$, and 10 at applied potentials of $-0.6,-0.7,-0.8,-0.9$, and $-1.0 \mathrm{~V}_{\mathrm{SCE}}$, respectively. $C_{\mathrm{H}-\mathrm{Diff}}$ is based on the TDS-established $\mathrm{H}$ uptake relationship in Fig. 4 and the dashed line is given by Eq. [9].

from $40 \mathrm{MPa} \sqrt{\mathrm{m}}$ results in $20<x^{2} / G<57 \mathrm{~cm}$, while a twofold rise in $K$ from $40 \mathrm{MPa} \sqrt{\mathrm{m}}$ results in $x^{2} / G$ of $12 \mathrm{~cm}$ for the $3.2 \mathrm{~mm}$ crack size typical of this high $K$ of $80 \mathrm{MPa} \sqrt{\mathrm{m}}$. Summarizing, $x^{2} / G$ will be 10 to $60 \mathrm{~cm}$ for the range of crack sizes and $K$ levels encountered in the crack growth experiments. The dotted line in Figure 5 describes crack tip $C_{\mathrm{H} \text {-Diff }} v s$ applied potential for Monel K-500 (aged, ATI Allvac) SENT specimens with $x^{2} / G$ of 10 to $60 \mathrm{~cm}$; the equation is:

$$
C_{\mathrm{H}-\text { Diff }}(w p p m)=-52.5-0.0687 E_{\mathrm{A}}\left(\mathrm{mV}_{\mathrm{SCE}}\right) .
$$

Crack tip $C_{\mathrm{H}, \text { diff }}$ decreases with increasing $E_{\mathrm{A}}$. Equation [9] shows that $\mathrm{H}$ enters the crack tip at all applied cathodic polarizations more negative than $-764 \mathrm{mV}_{\mathrm{SCE}}$.

\section{B. Baseline Crack Growth in $\mathrm{N}_{2}$}

The results of a slow-rising $K$ experiment $(\mathrm{d} K / \mathrm{d} t=$ $1 \mathrm{MPa} \sqrt{\mathrm{m}} / \mathrm{h})$ in low humidity $\mathrm{N}_{2}(\mathrm{RH}<10 \mathrm{pct})$ are shown in Figure 6 and suggest two regimes of behavior. For $10<K<35 \mathrm{MPa} \sqrt{\mathrm{m}} \mathrm{dcPD}$ rises with $K$ to produce $\mathrm{d} a / \mathrm{d} t$ on the order of 0.1 to $0.3 \mathrm{~nm} / \mathrm{s}$, which is not true crack advance. These false growth rates are due to crack tip plasticity, which causes increased alloy resistivity, and blunting. Highly localized plasticity is not corrected by remote-reference probe normalization. The data in this low- $K$ regime are fit $\left[\log \mathrm{d} a / \mathrm{d} t_{\text {FALSE }}\right.$ $(\mathrm{mm} / \mathrm{s})=-6.96+0.01 \mathrm{~K}(\mathrm{MPa} \sqrt{\mathrm{m}})]$ to establish a resolution limit. Similar-false $\mathrm{d} a / \mathrm{d} t$ behavior was observed for an ultra-high strength steel, which did not exhibit crack growth based on scanning electron microcopy (SEM). ${ }^{[72]}$

The second regime in Figure 6(a) shows $\mathrm{d} a / \mathrm{d} t$ rising above the resolution limit for $K_{\mathrm{J}}$ greater than $40 \mathrm{MPa} \sqrt{\mathrm{m}}$. SEM analysis revealed a $700 \mu \mathrm{m}$ wide zone of crack advance in the central portion of the SENT specimen (Figure 6(b)). This region is bounded by the fatigue precrack (right) and region where the applied load exceeded the limit load of the material (left). This extent of cracking during 45 hours of rising $K$ from 40 to $85 \mathrm{MPa} \sqrt{\mathrm{m}}$ suggests an average $\mathrm{d} a / \mathrm{d} t$ of $4 \times 10^{-6} \mathrm{~mm} / \mathrm{s}$. Higher resolution SEM analysis (Figure 6(c)) of the central region revealed features consistent with microvoid damage. The estimated upper bound of the stretch zone due to crack tip blunting equals CTOD and is $\approx 25 \mu \mathrm{m}$ at $K_{\mathrm{J}}$ of $80 \mathrm{MPa} \vee \mathrm{m}^{\dagger}$; this

${ }^{\dagger}$ CTOD equals $d_{n} K_{\mathrm{J}}^{2}\left(1-v^{2}\right) /\left(\sigma_{\mathrm{YS}} E\right)^{[60]}$, where $d_{n}=0.69$ for the average of plane stress and plane strain, and using the RambergOsgood flow properties for aged Monel K-500.

is small compared to the observed crack growth $(700 \mu \mathrm{m})$.

\section{HEAC under Severe Cathodic Polarization}

Aged Monel K-500 is susceptible to severe HEAC under slow-rising $K$ during immersion in $\mathrm{NaCl}$ at constant-cathodic $E_{\mathrm{A}}$ of $-1000 \mathrm{mV}_{\mathrm{SCE}}$. Figure 7 shows the results of a single experiment, plotted as $\mathrm{d} a / \mathrm{d} t$ vs elastic $K$ at constant $\mathrm{d} K / \mathrm{d} t$ of $0.33 \mathrm{MPa} \sqrt{\mathrm{m}} / \mathrm{h}$ for $K$ from 6 to 43.9 MPa $\sqrt{\mathrm{m}}$ and $\mathrm{d} K / \mathrm{d} t=1.1 \mathrm{MPa} \sqrt{\mathrm{m}} / \mathrm{h}$ for $K$ above 43.9 $\mathrm{MPa} \sqrt{\mathrm{m}}$. A second experiment showed identical $\mathrm{d} a / \mathrm{d} t$ vs $K$, confirming reproducibility. ${ }^{[55]}$ The initial decline in $\mathrm{d} a / \mathrm{d} t$ with rising $K$ is not real; rather, it is due to crack surface electrical contact, which declines with rising $K$. Increasing voltage, at a declining rate with crack opening, is reasonable for Monel K-500 in $\mathrm{NaCl}$ because: (a) cathodic polarization likely reduced the fatigue crack surface oxide that would provide electrical insulation, and (b) the fatigue crack was microscopically rough due to slip band cracking to promote asperity contact (top part of Figure 8(a)). Falling $\log \mathrm{d} a / \mathrm{d} t$ was fit as a linear function of $\log K$ and subtracted from measured $\mathrm{d} a / \mathrm{d} t$ to produce real growth rates. Correction of measured $\mathrm{d} a / \mathrm{d} t$ (filled data points in Figure 7) is illustrated by the solid line and open points. The corrected $\mathrm{d} a / \mathrm{d} t$ vs $K$ relationship in Figure 7 conforms to the kinetics typical of HEAC. ${ }^{[13]} \mathrm{An}$ apparent $K_{\mathrm{TH}}$ for the onset of subcritical crack growth under slow-rising $K$ is followed by steeply rising $\mathrm{d} a / \mathrm{d} t$, and transitioning to the beginning of a reasonably $K$-independent (Stage II) crack growth rate regime above about $4 \times 10^{-5} \mathrm{~mm} / \mathrm{s}$. The programmed increase of $\mathrm{d} K / \mathrm{d} t$ at $K=44 \mathrm{MPa} \sqrt{\mathrm{m}}$ did not resolvably affect $\mathrm{d} a / \mathrm{d} t$. The $K_{\mathrm{TH}}$, operationally defined in a subsequent section, is $22 \mathrm{MPa} \sqrt{\mathrm{m}}$ in Figures 7 and $17 \mathrm{MPa} \sqrt{\mathrm{m}}$ for the replicate experiment. These $K_{\mathrm{TH}}$ are low compared to the plane strain fracture toughness for this alloy in the range of 198 to $340 \mathrm{MPa} \sqrt{\mathrm{m}} .{ }^{[28,30,73]}$

The HEAC path was IG for the test conditions in Figure 7, as established by the SEM fractographs in Figure 8. The low magnification image (Figure 8(a)) shows the moist air fatigue precrack front transition to IG HEAC. Air fatigue in this alloy stressed at low stress intensities involves faceted $\{111\}$ slip band cracking, plus limited IG cracking. ${ }^{[74]}$ The transition from fatigue crack 


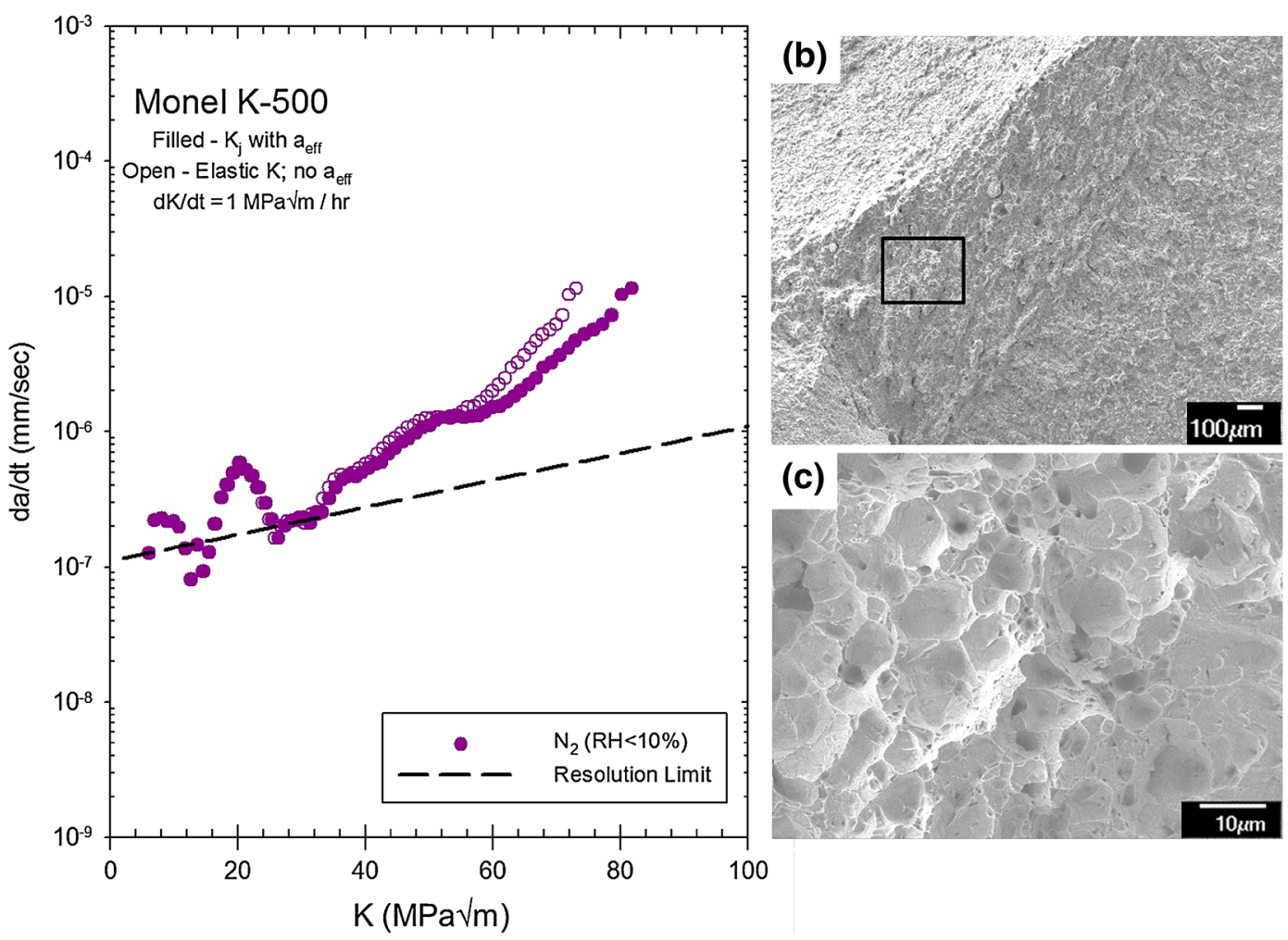

(a)

Fig. 6-(Color online) (a) Crack growth rate vs $K$ (elastic, open and elastic-plastic, filled) for aged Monel K-500 (ATI Allvac, Table I) stressed at constant $\mathrm{d} K / \mathrm{d} t$ of $1 \mathrm{MPa} \sqrt{\mathrm{m}} / \mathrm{h}$ in low humidity $\mathrm{N}_{2}$. The dotted line shows the resolution limit corresponding to false $\mathrm{d} a / \mathrm{d} t$ from crack tip plastic deformation. SEM fractographs in $(b)$ and $(c)$ demonstrate crack growth (right to left) of a ductile morphology.

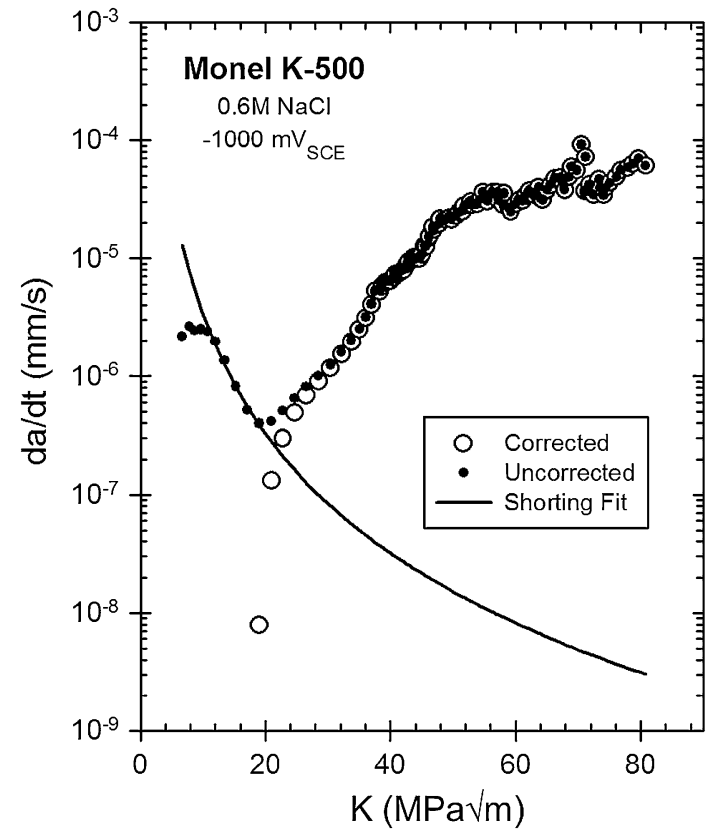

Fig. 7-Measured $\mathrm{d} a / \mathrm{d} t$ vs elastic $K$ for aged Monel K-500 (ATI Allvac, Table I) stressed under the slow-rising $K$ protocol in $\mathrm{NaCl}$ solution at $E_{\mathrm{A}}$ of $-1000 \mathrm{mV}_{\mathrm{SCE}}$.

to $\mathrm{H}$ crack is traced in Figure 8(a) and was observed during SEM analyses of all specimens. This low magnification fractograph is compared to an SEM image
(Figure 8(b)) of the Monel K-500 microstructure showing good correspondence between grain size and IG facet size. Figures 8(c) and (d) suggest that grain surfaces are populated by slip steps, which interact with grain boundaries as reported for IHAC of $\mathrm{Ni}^{\left[{ }^{[38,39]}\right.}$ The particles in Figure 8(b) are large $\mathrm{TiC}$ and sulfide inclusions (rich in $\mathrm{Mg}, \mathrm{Mn}, \mathrm{Al}, \mathrm{Ti}$, and $\mathrm{Fe}$ based on energy dispersive analysis ${ }^{[29]}$ and were occasionally present on IG surfaces. The fine particles in Figure 8(d) were not identified, but were observed on IG facets produced at other cathodic potentials. These particles are sized ( $\sim 50 \mathrm{~nm}$ diameter) on the scale of $\mathrm{Ni}_{3}(\mathrm{Al}, \mathrm{Ti})$ precipitates. ${ }^{\text {[59] }}$

\section{Effect of Applied Potential on HEAC}

The severity of HEAC in aged Monel K-500 increases with increasing cathodic polarization between -700 and $-1100 \mathrm{mV}_{\mathrm{SCE}}$, as established in Figure 9. Polarization current was nearly constant at each fixed $E_{\mathrm{A}}$ and always cathodic. $K_{\mathrm{TH}}$ is defined as the stress intensity level necessary to produce a $\mathrm{d} a / \mathrm{d} t$ equal to the resolution limit represented by the dotted lines in Figure 9."

\footnotetext{
${ }^{*}$ The levels of crack tip plasticity and false dcPD rise are expected to be independent of loading rate. As such, the false growth rate for $\mathrm{d} K / \mathrm{d} t=1 \mathrm{MPa} \sqrt{\mathrm{m}} / \mathrm{h}$ (Fig. 6: $\log \mathrm{d} a / \mathrm{d} t_{\mathrm{FALSE}}(\mathrm{mm} / \mathrm{s})=-6.96+$ $0.01 \mathrm{~K}(\mathrm{MPa} \sqrt{\mathrm{m}}))$ scales linearly with $\mathrm{d} K / \mathrm{d} t$ to yield the loading rate specific resolution limit on $\mathrm{d} a / \mathrm{d} t$.
} 

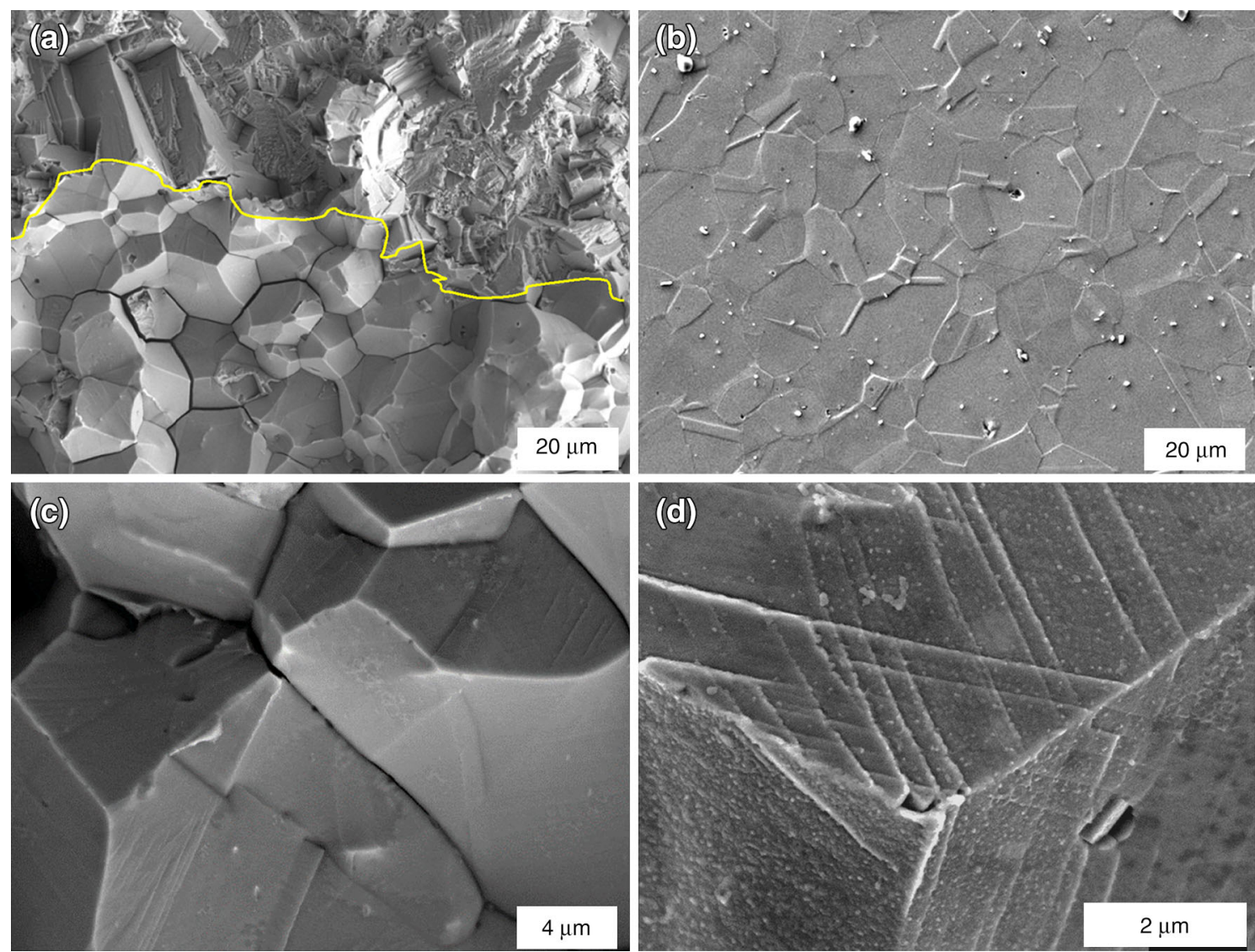

Fig. 8-(Color online) $(a),(c),(d)$ Scanning electron fractographs for aged Monel K-500 (ATI Allvac, Table I), stressed under d $K / \mathrm{d} t$ of $0.3 \mathrm{MPa} \sqrt{\mathrm{m}} / \mathrm{h}$ in $\mathrm{NaCl}$ solution at $E_{\mathrm{A}}$ of $-1000 \mathrm{mV}_{\mathrm{SCE}}$, showing IG HEAC transitioning from the mixed TG-IG fatigue crack front outlined in (a). Crack growth is from top to bottom in each image. (b): Scanning electron micrograph of polished and etched Monel K-500.

Table III summarizes these $K_{\mathrm{TH}}$ values, as well as data obtained for a second lot of aged Monel K-500 defined in Footnote *. All cracks grew in a flat Mode I morphology, with the exception of two experiments at $-850 \mathrm{mV}_{\mathrm{SCE}}$, which deflected out-of-plane after the onset of growth at $K_{\mathrm{TH}}$. As such, the listed d $a / \mathrm{d} t$ values may not be accurate and these two experiments are not included in Figure 9.

Three trends are apparent in Figure 9 and Table III. First, $K_{\mathrm{TH}}$ increases as $E_{\mathrm{A}}$ becomes more positive from -1100 to $-700 \mathrm{mV}_{\mathrm{SCE}}$. Second, crack growth rates approaching a Stage II plateau decrease with increasing potential. Third, the step increase in $\mathrm{d} K / \mathrm{d} t$ (from 0.33 to $1.1 \mathrm{MPa} \sqrt{\mathrm{m}} / \mathrm{h}$ ) at $K$ of $44 \mathrm{MPa} \sqrt{\mathrm{m}}$ had no resolvable effect on $\mathrm{d} a / \mathrm{d} t$ at $-1100 \mathrm{mV}_{\mathrm{SCE}}$, but caused a step increase in $\mathrm{d} a / \mathrm{d} t$ at $-800,-750$, and $-700 \mathrm{mV}_{\mathrm{SCE}}$. For these higher potentials, Figure 9 shows an instantaneous 3.3-times increase in $\mathrm{d} a / \mathrm{d} t$ at $K=43.9 \mathrm{MPa} \sqrt{\mathrm{m}}$, which equals the 3.3-times increase in applied $\mathrm{d} K / \mathrm{d} t$.

For $E_{\mathrm{A}}$ between -1100 and $-900 \mathrm{mV}_{\mathrm{SCE}}$, HEAC in Monel K-500 was macroscopically uniform through the SENT thickness and fully IG based on SEM analysis (e.g., Figure 8). However, fractographic analysis of the $-800 \mathrm{mV}_{\mathrm{SCE}}$ case (Figure 10) showed a mixed IG and TG morphology. The TG features suggest $\mathrm{H}$ interaction with slip to produce facets possibly parallel to intersecting slip planes. This TG cracking may be related to the lower $\mathrm{H}$ content produced at the crack tip for this higher potential, consistent with $\mathrm{d} a / \mathrm{d} t$ levels that decrease with increasingly positive $E_{\mathrm{A}}$ (Figure 9; Table III). SEM fractography of the $-700 \mathrm{mV}_{\mathrm{SCE}}$ (Figures 11(a) and (b)) and $-750 \mathrm{mV}_{\mathrm{SCE}}$ (Figures 11(c) and (d)) specimens did not evidence IG cracking. Rather, the crack surfaces produced in $\mathrm{NaCl}$ exhibited TG features similar to those observed for the low humidity $\mathrm{N}_{2}$ experiment. Crack extension occurred in the central portion of each SENT specimen and was populated by microvoid features. The fractograph of the $-700 \mathrm{mV}_{\mathrm{SCE}}$ specimen in Figure 11(a) shows the fatigue precrack in the top-third of the image, a $75 \mu$ m-wide-zone (middle) associated with slow-rising $K$ loading in $\mathrm{NaCl}$, and post-test fatigue in moist air (bottom third). The middle zone created by cracking in $\mathrm{NaCl}$ consists of dimple-like features without IG facets (Figure $11(\mathrm{~b})$ ). For the $-750 \mathrm{mV}_{\mathrm{SCE}}$ case, Figure 11(c) shows a larger TG zone $(\sim 450 \mu \mathrm{m})$ in the central portion of the specimen, created during loading in $\mathrm{NaCl}$ and flanked by the fatigue precrack (left) and post-test fatigue (right). This middle zone is TG-dimpled, without evidence of IG features (Figure 11(d)).

\section{E. Effect of Loading Protocol on HEAC}

Loading protocol appears to significantly impact crack growth in aged Monel K-500, predominantly at 
the less-cathodic potentials where resistance to HEAC is high. This behavior was examined at $-800 \mathrm{mV}_{\mathrm{SCE}}$ by comparing crack growth during continuously slowrising $K$ (Figures 9 and 10) with a set of fast-rising step $(1.5 \mathrm{MPa} \sqrt{\mathrm{m}}$ step at $\mathrm{d} K / \mathrm{d} t=7 \mathrm{MPa} \sqrt{\mathrm{m}} / \mathrm{h})$ then constant $K$ hold (6 hours) segments. The SEM images in Figure 12 are striking. Figure 12(a) shows that $580 \mu \mathrm{m}$ of uniform IG EAC (Figure 10) occurred during slowrising $K$ from an elastic $K_{\mathrm{TH}}$ of $42 \mathrm{MPa} \sqrt{\mathrm{m}}$ to a finalelastic $K$ of $59.2 \mathrm{MPa} \sqrt{\mathrm{m}}$ (Figure 9 ) over 132.3 hours. A smaller amount of stable crack growth was observed for

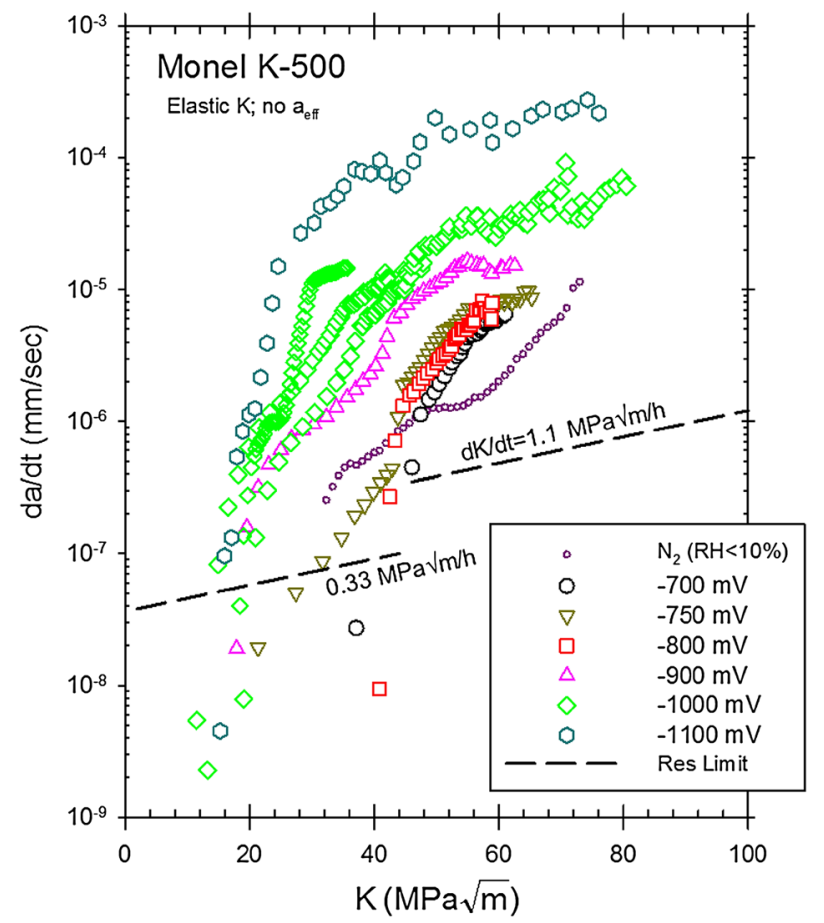

Fig. 9-(Color online) Crack growth rate vs elastic $K$ for aged Monel K-500 (ATI Allvac; Table I) stressed under the slow $\mathrm{d} K / \mathrm{d} t$ protocol in $\mathrm{NaCl}$ solution at various constant $E_{\mathrm{A}}$ between -700 and $-1100 \mathrm{mV}_{\mathrm{SCE}}$ Constant $\mathrm{d} K / \mathrm{d} t$ was $0.33 \mathrm{MPa} \sqrt{\mathrm{m}} / \mathrm{h}$ for $K<43.9 \mathrm{MPa} \sqrt{\mathrm{m}}$ and $1.1 \mathrm{MPa} \vee \mathrm{m} / \mathrm{h}$ for $K>43.9 \mathrm{MPa} \sqrt{\mathrm{m}}$. The dotted lines show the expected false $\mathrm{d} a / \mathrm{d} t$ produced by crack tip plastic deformation for each $\mathrm{d} K / \mathrm{d} t$. the step-hold case, with a final-elastic $K$ of $53.5 \mathrm{MPa} \sqrt{\mathrm{m}}$ and total loading time of 120.7 hours. Critically, the crack path was TG with microvoids in the center of the SENT specimen (Figure 12(b)). This morphology is similar to that shown in Figures 6 and 11 for rising $K$ loading in $\mathrm{N}_{2}$, as well as in $\mathrm{NaCl}$ at -700 and $-750 \mathrm{mV}_{\mathrm{SCE}}$ where HEAC did not occur.

Crack length during several hold periods is presented in Figure 13. From regression analysis, $\mathrm{d} a / \mathrm{d} t$ values are $5.6 \times 10^{-8}, 1.3 \times 10^{-8}$, and $1.4 \times 10^{-7} \mathrm{~mm} / \mathrm{s}$ for $K$ of $50.3,51.9$, and $53.5 \mathrm{MPa} \sqrt{ } \mathrm{m}$, respectively. These growth rates are associated with the real-stable crack growth indicated in Figure 12(b). The step increases in crack length were caused by crack tip deformation-based dcPD increase (false growth) plus real microvoid-based crack growth. Total crack growth was $276 \mu \mathrm{m}$ from dcPD, overestimated due to crack tip plasticity and in reasonable agreement with the largest crack length change $(250 \mu \mathrm{m})$ shown in Figure 12(b). These rates of crack growth are at least 30 times less than the $\mathrm{d} a / \mathrm{d} t$ characteristic of IGSCC at this $E_{\mathrm{A}}$ and slow-rising $K$, $4 \times 10^{-6} \mathrm{~mm} / \mathrm{s}$ at $53.5 \mathrm{MPa} \sqrt{\mathrm{m}}$ from Figure 9. Moreover, each of these hold-period $K$ levels is above the $K_{\mathrm{TH}}$ for slow-rising loading. The results in Figures 12 and 13 suggest that step-hold $K$ loading does not produce any IG EAC, which was created during slow-rising $K$ loading, but did produce limited ductile crack growth as observed for other loading and environmental conditions. Experiments at higher $K$ levels are required to examine this loading protocol effect.

Both slow rising and step-hold stress intensity protocols yielded the same rates of HEAC in aged Monel K-500 (Footnote *) when the specimens were stressed at $-934 \mathrm{mV}_{\mathrm{SCE}}$, which favored higher rates of subcritical cracking.

\section{F. Elastoplastic Analysis}

Neither macroscopic through-thickness plasticity, nor shear walls along specimen edges were associated with the HEAC results in Figure 9. Nonetheless, the highelastic $K$ achieved near the end of the experiments and relatively low strength of Monel K-500 necessitate

Table III. HEAC Growth Rate Properties for Aged Monel K-500 (ATI Allvac; Tables I and II)

\begin{tabular}{|c|c|c|c|c|}
\hline$E_{\mathrm{A}}\left(\mathrm{mV} V_{\mathrm{SCE}}\right)$ & $\begin{array}{l}K_{\mathrm{TH}}(\text { elastic }) \\
(\mathrm{MPa} \sqrt{\mathrm{m}})\end{array}$ & $\begin{array}{l}K_{\mathrm{TH}}(J \text {-integral }) \\
(\mathrm{MPa} \sqrt{\mathrm{m}})\end{array}$ & $\begin{array}{c}\mathrm{d} a / \mathrm{d} t_{\mathrm{II}} \text { from dcPD at } \\
\text { elastic } K=50 \mathrm{MPa} \sqrt{\mathrm{m}}(\mathrm{mm} / \mathrm{s})\end{array}$ & IG cracking \\
\hline-1100 & 17 & 17 & $1.7 \times 10^{-4}$ & yes \\
\hline-1000 & 20 & 20 & $2.3 \times 10^{-5}$ & yes \\
\hline-1000 & 16 & 16 & $1.9 \times 10^{-5}$ & yes \\
\hline-1000 & 18 & 18 & $1.8 \times 10^{-5}$ & yes \\
\hline-934 Footnote $*$ & $\sim 30$ & $\sim 31$ & $1.6 \times 10^{-5}$ & yes \\
\hline-900 & 19 & 19 & $1.1 \times 10^{-5}$ & yes \\
\hline-850 & 38 & 39 & $3.7 \times 10^{-6}$ deflected & not examined \\
\hline-850 & 41 & 44 & $2.5 \times 10^{-6}$ deflected & not examined \\
\hline-800 & 42 & 45 & $3.0 \times 10^{-6}$ & yes \\
\hline-750 & $>68$ & $>90$ & $\mathrm{~N} / \mathrm{A}$ & no \\
\hline-700 & $>63$ & $>77$ & $\mathrm{~N} / \mathrm{A}$ & no \\
\hline-700 Footnote * & $>63$ & $>77$ & $\mathrm{~N} / \mathrm{A}$ & no \\
\hline
\end{tabular}



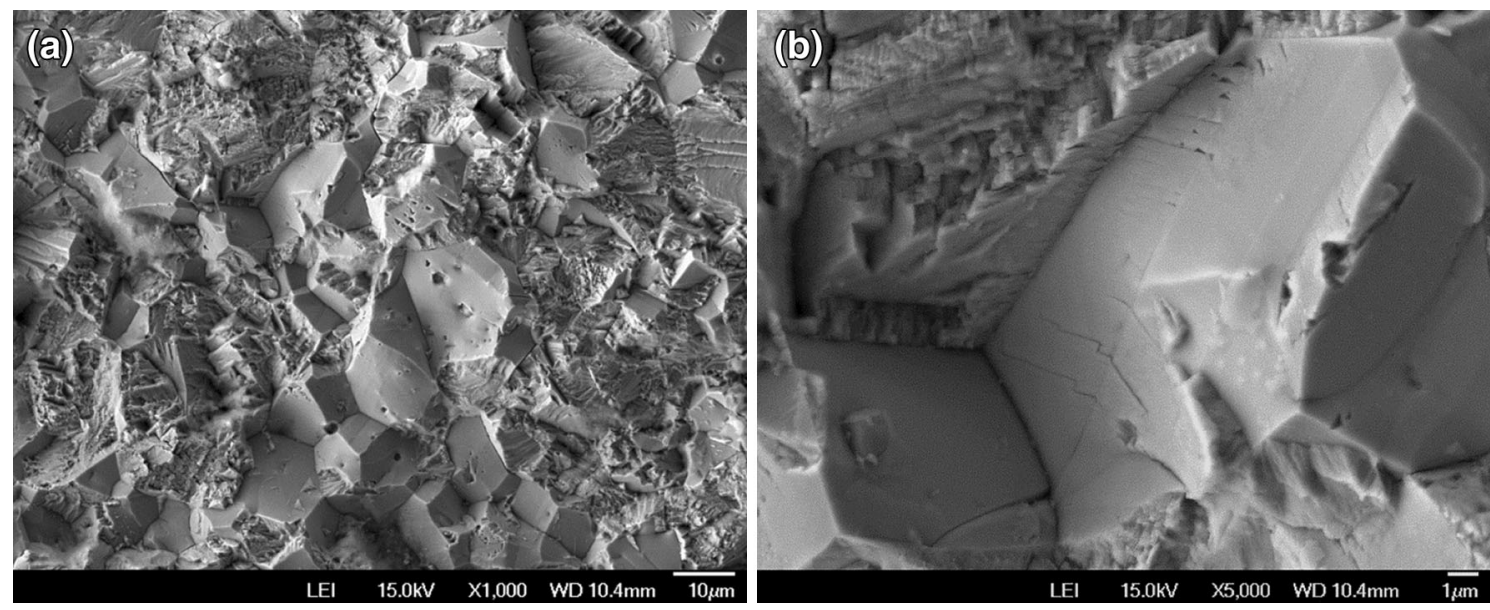

Fig. 10 - Scanning electron fractographs of aged Monel K-500 (ATI Allvac; Table I), stressed under slow-rising $K$ in NaCl solution at $E_{\mathrm{A}}$ of $-800 \mathrm{mV}_{\mathrm{SCE}}$, showing mixed IG-TG HEAC without microvoids.
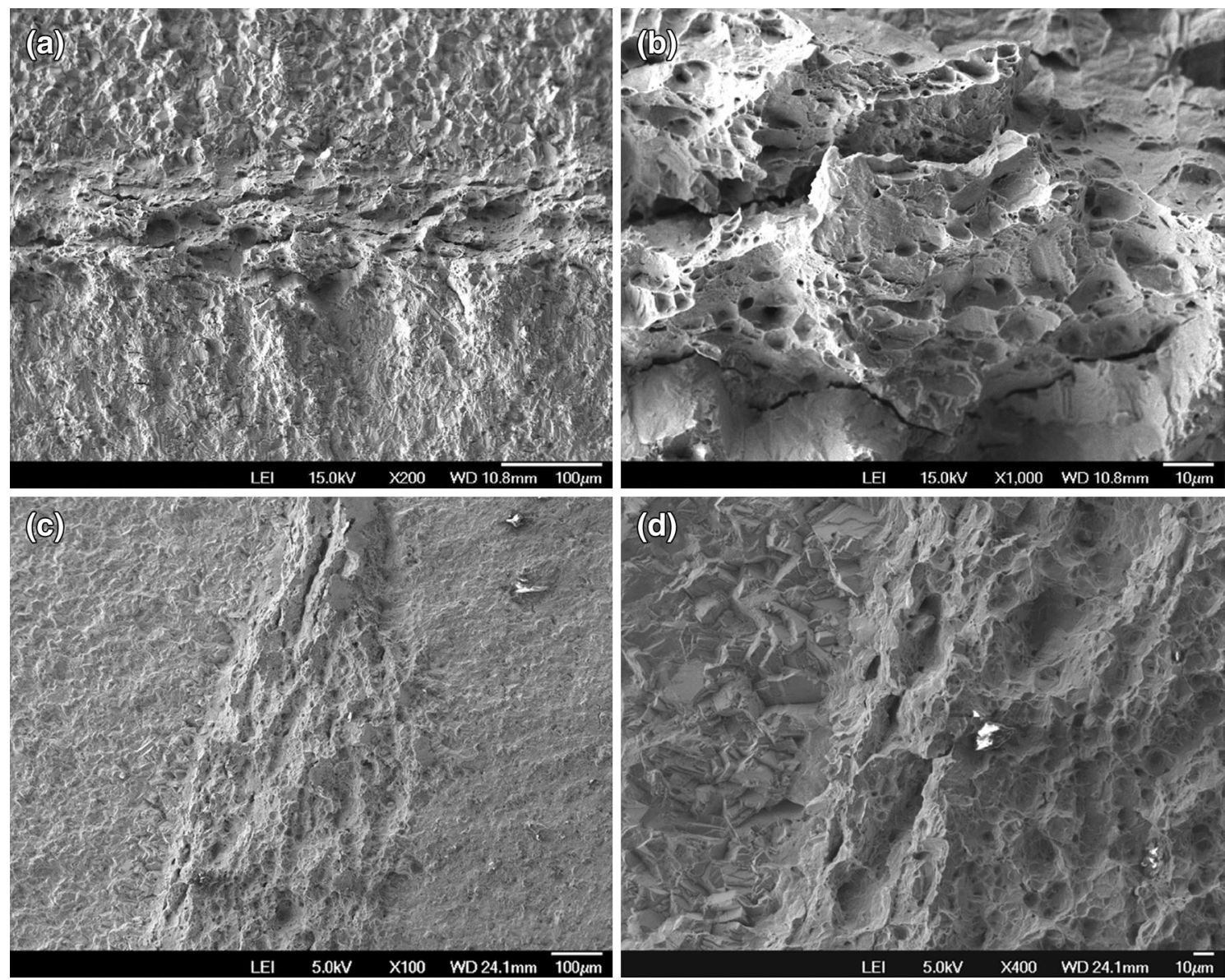

Fig. 11-Scanning electron fractographs of aged Monel K-500 (ATI Allvac; Table I) stressed under the slow-rising $K$ protocol in NaCl at $E_{\mathrm{A}}$ of: (a) and $(b)-700 \mathrm{mV}_{\mathrm{SCE}}$, showing a lack of resolvable IG HEAC ahead of the fatigue crack front (middle of each image) with growth from top to bottom; and $(c)$ and $(d)-750 \mathrm{mV}_{\mathrm{SCE}}$, showing a lack of IG cracking ahead of the fatigue crack (middle of each image) with growth from left to right.

assessment of the effect of uncracked ligament plasticity on stress intensity. Results are presented in Figure 14, which is a plot of $\mathrm{d} a / \mathrm{d} t$ vs elastic $K$ (open symbols, plotted from Figure 9), and elastoplastic $K_{\mathrm{J}}$ (filled symbols) from the $J$-integral analysis of the SENT geometry. These results demonstrate no impact of plasticity for elastic $K$ below about $40 \mathrm{MPa} \sqrt{ }$ m. However, elastoplastic analysis yields up to a 25 pct increase 

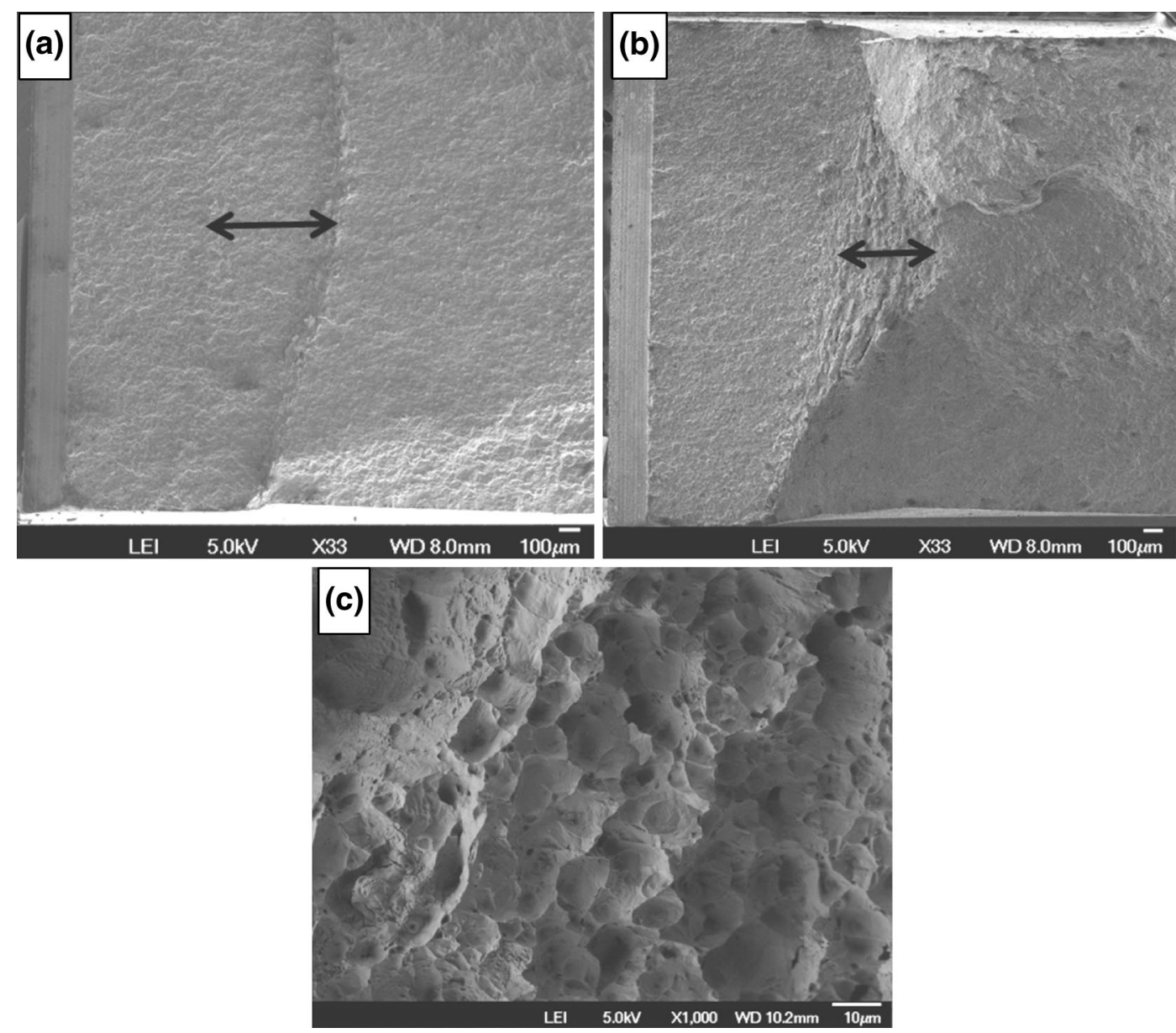

Fig. 12-SEM fractographs showing the effect of: $(a)$ continuous-rising $K(\mathrm{~d} K / \mathrm{d} t=0.33 \mathrm{MPa} \sqrt{\mathrm{m}} / \mathrm{h}$ then $1.1 \mathrm{MPa} \sqrt{\mathrm{m}} / \mathrm{h}) v s(b)$ and $(c)$ step-hold $K(2.6 \mathrm{MPa} \sqrt{\mathrm{m}}$ step at $7 \mathrm{MPa} \sqrt{\mathrm{m}} / \mathrm{h}$ and $6 \mathrm{~h}$ hold; repeated) for aged Monel K-500 (ATI Allvac; Table I) stressed in NaCl solution at $-800 \mathrm{mV}_{\mathrm{SCE}}$.

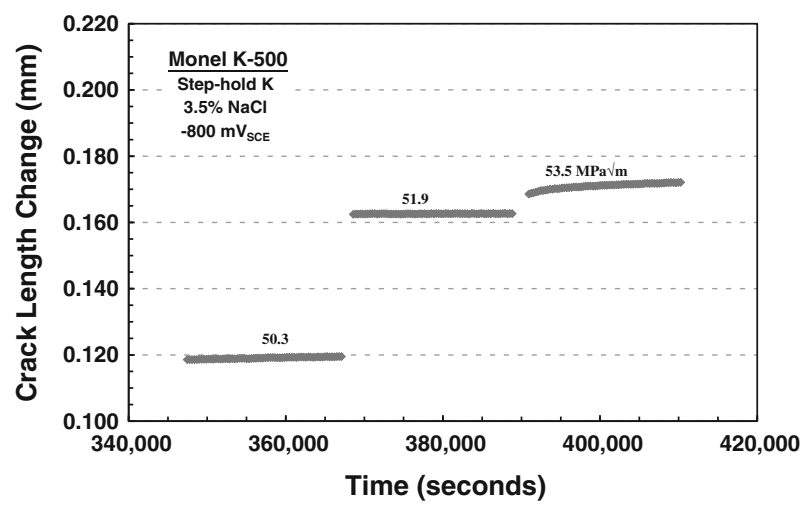

Fig. 13- Crack length change ahead of the fatigue precrack $v s$ loading time for aged Monel K-500 (ATI Allvac; Table I) stressed under the fast-rise plus hold protocol at the indicated-constant elastic $K$ levels during exposure in $\mathrm{NaCl}$ solution at $-800 \mathrm{mV}_{\mathrm{SCE}}$. Average $\mathrm{d} a / \mathrm{d} t$ from regression analysis of each data set is $5.6 \times 10^{-8}$, $1.3 \times 10^{-8}$, and $1.4 \times 10^{-7} \mathrm{~mm} / \mathrm{s}$ for the low to high $K$ levels, respectively.

in $K$ to $K_{\mathrm{J}}$, with the strongest influence on experiments conducted with cathodic polarization above $-800 \mathrm{mV}_{\mathrm{SCE}} . K_{\mathrm{TH}}$ values are only mildly increased
(Table III) and the estimated levels of $\mathrm{d} a / \mathrm{d} t_{\mathrm{II}}$ are unaffected by this plasticity correction.

\section{DISCUSSION}

A. Accelerated-Quantitative Laboratory Characterization of EAC in Monel K-500

The rising $K$ small crack test method successfully characterized IG EAC in aged Monel K-500, providing quantitative $K_{\mathrm{TH}}$ and d $a / \mathrm{d} t$ vs $K$ data (Figures 9 and 14). Continuously recorded high resolution crack length measurement by dcPD, and the potentially damaging role of concurrent straining and $\mathrm{H}$ uptake, provides the basis for this accelerated test method. The steps necessary to obtain high resolution measurements of low growth rates were summarized in Section III and elsewhere. ${ }^{[72]}$

If an alloy is susceptible to HEAC, such as Monel K-500 under severe cathodic polarization in chloride solution, then cracking kinetics are similar for rising $K$ and quasi-static $K$ or step-hold loading; dcPD monitoring of the small crack to yield $K_{\mathrm{TH}}$ and $\mathrm{d} a / \mathrm{d} t v_{s} K$ is the primary attribute of this method. Measurement of $\mathrm{d} a / \mathrm{d} t$ 


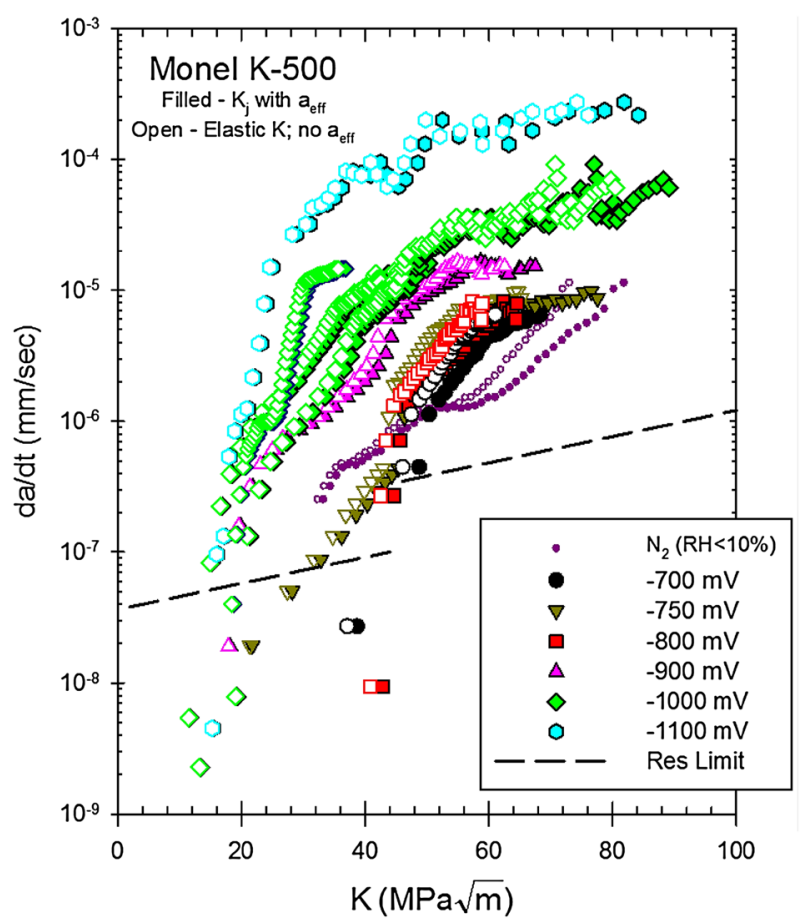

Fig. 14 (Color online) $\mathrm{d} a / \mathrm{d} t$ vs $K$ for aged Monel K-500 (ATI Allvac; Table I) stressed under slow-rising $K$ in $\mathrm{NaCl}$ solution at various constant $E_{\mathrm{A}}$ between -700 and $-1100 \mathrm{mV}_{\mathrm{SCE}} . \mathrm{d} a / \mathrm{d} t$ is plotted $v s$ elastic $K$ (open) from Fig. 9 and elastic-plastic $K_{\mathrm{J}}$ (filled). The constant $\mathrm{d} K / \mathrm{d} t$ was $0.33 \mathrm{MPa} \sqrt{\mathrm{m}} / \mathrm{h}$ for $K<43.9 \mathrm{MPa} \sqrt{\mathrm{m}}$, then $1.1 \mathrm{MPa} \sqrt{\mathrm{m}} / \mathrm{h}$ for higher $K$. The dotted lines show estimated-false $\mathrm{d} a / \mathrm{d} t$ produced by crack tip plastic deformation for each $\mathrm{d} K / \mathrm{d} t$.

over short-crack extension and time (days to weeks) provides the basis to predict cracking over longer times in alternate geometries, following fracture mechanics similitude. ${ }^{[72]}$ The rapid rise in $\mathrm{d} a / \mathrm{d} t$ above the apparent $K_{\mathrm{TH}}$ enables such long-term predictions. However, for alloys which resist environmental cracking leading to a strong role of crack tip plasticity in HEAC, ${ }^{[49]}$ or if crack tip surface condition or reaction interacts with HEAC, then rising $K$ likely lowers $K_{\mathrm{TH}}$ and increases $\mathrm{d} a / \mathrm{d} t$ compared to quasi-static loading, as observed in Figures 12 and 13. In such cases crack tip strain and strain rate are important variables. ${ }^{[13,49,75]}$ Current results suggest that rising $K$ at a sufficiently slow $\mathrm{d} K / \mathrm{d} t$ provides identical (for susceptible alloy-environment conditions) to conservative (for resistant alloy-environment) values of HEAC threshold and kinetics. ${ }^{[13,49]}$

The HEAC properties in Figure 14, from elastoplastic $K_{\mathrm{J}}$ analysis of a small specimen, are quantitatively relevant to a structure under elastic loading, following the $J$-integral approach. ${ }^{[58,60,66,67,76-78]}$ To verify this assertion, it is necessary to demonstrate $K$ and $J$ dominance of crack tip mechanics. ${ }^{[52]} K$ dominance is established by comparing the uncracked SENT ligament $(W-a)$ and plane strain plastic zone diameter (estimated using the Ramberg-Osgood flow properties for Monel K-500) for the deepest crack and high-elastic $K$ of $50 \mathrm{MPa} \sqrt{\mathrm{m}}$. For these conditions, the uncracked ligament is six times larger than the plastic zone diameter, suggesting that $K$ governs crack tip stress and strain distributions, as supported by FEA analysis. ${ }^{[52]}$ For elastoplastic deformation of a small specimen, $J$ dominance requires $(W-a)$ to be greater than $\mathrm{MJ} / \sigma_{\mathrm{o}}$, where $M$ ranges from 25 to 200 for pure bending and tension, respectively. ${ }^{[79,80]}$ At a $K_{\mathrm{J}}$ of $80 \mathrm{MPa} \sqrt{\mathrm{m}}, M$ is 100 and $\mathrm{MJ} /$ $\sigma_{\mathrm{o}}$ equals $3.9 \mathrm{~mm}$ for HEAC susceptible Monel K-500 with an uncracked ligament length of $6 \mathrm{~mm}$. For HEAC resistant Monel K-500, with a typical uncracked ligament length of $9 \mathrm{~mm}, M$ is 175 , and $\mathrm{MJ} / \sigma_{\mathrm{o}}$ equals $6.8 \mathrm{~mm}$. Even at this high $K_{\mathrm{J}}$ level, the criteria for $J$ dominance are satisfied for the small SENT specimen under both HEAC resistant and susceptible conditions. Furthermore, the $\mathrm{d} a /$ $\mathrm{d} t$ vs $K$ relationships in Figure 14 demonstrate a classic Stage I-Stage II shape; loss of $K$ or $J$ dominance should cause a departure from this behavior.

Crack tip constraint similitude must also be considered when applying experimentally derived HEAC threshold and kinetics properties (Figure 14) in a component assessment. A plane strain continuum finite element analysis demonstrated that crack tip stress, strain, and dislocation-trapped $C_{\mathrm{H}-\mathrm{Diff}}$ fields in a small SENT specimen of an alloy steel $\left(\sigma_{\mathrm{o}}=595 \mathrm{MPa}\right.$ and $n=17$ ) stressed to $K$ of $34 \mathrm{MPa} \sqrt{\mathrm{m}}$ in high pressure $\mathrm{H}_{2}$ are well described by $K$ and $J^{[52]}$ Each field changed mildly as HEAC progressed from a low constraint condition at $a / W$ of $0.08\left(T=-0.3 \sigma_{\mathrm{o}}\right.$, where $T$ is $T$-stress) to modest constraint $\left(T=+0.002 \sigma_{\mathrm{o}}\right)$ at $a / W$ of $0.6 .^{[52]}$ These constraint levels are typical of a smallsurface crack subjected to tension or bending.

\section{B. HEAC Susceptibility of Monel K-500}

Aged Monel K-500 is susceptible to HEAC when stressed in $\mathrm{NaCl}$ solution at potentials substantially cathodic to the OCP of -200 to $-250 \mathrm{mV}_{\text {SCE}}$. Crack growth rates (Figures 7, 9, and 14) and SEM analyses (Figures 8 and 10) show severe IG HEAC for $-1100 \mathrm{mV}_{\mathrm{SCE}}<E_{\mathrm{A}}<-850 \mathrm{mV}_{\mathrm{SCE}}$, and slower but finite $\mathrm{d} a / \mathrm{d} t$ at $-800 \mathrm{mV}_{\mathrm{SCE}}$ with slow-rising $K$. Polarization to either -700 or $-750 \mathrm{mV}_{\mathrm{SCE}}$ eliminated resolvable IG HEAC for the loading rate investigated. Such cracking was also eliminated for static $K$ loading at $-800 \mathrm{mV}_{\mathrm{SCE}}$.

The beneficial effect of reduced cathodic polarization is consistent with limited literature results. Slow strain rate tensile experiments in artificial seawater showed severe EAC at $-1000^{[31]}$ and $-945 \mathrm{mV}_{\mathrm{SCE}}{ }^{[2]}$ high resistance at $-850 \mathrm{mV}_{\mathrm{SCE}},{ }^{[31]}$ and possible immunity at $-645 \mathrm{mV}_{\mathrm{SCE}}{ }^{\text {[2]; }}$ consistent with the fracture mechanics measurements in Figure 14 and Table III. Threshold stress intensity values for EAC in aged Monel K-500 $\left(R_{\mathrm{C}} 30\right.$ and $\left.\sigma_{\mathrm{YS}}=813 \mathrm{MPa}\right)$ stressed in 3.5 pct $\mathrm{NaCl}$ solution were reported based on the rising step load (RSL) method. ${ }^{[28]} K_{\mathrm{TH}}$ ranged from $18.4 \mathrm{MPa} \sqrt{\mathrm{m}}$ at $-1200 \mathrm{mV}_{\mathrm{SCE}}$ and $19.3 \mathrm{MPa} \sqrt{\mathrm{m}}$ at $-1000 \mathrm{mV}_{\mathrm{SCE}}$, to above $75 \mathrm{MPa} \sqrt{\mathrm{m}}$ at both -850 and $-700 \mathrm{mV}$ SCE. This study did not report growth rates, the resolution of crack growth monitoring, the effect of plasticity on $K_{\mathrm{TH}}$, or SEM analysis of EAC. ${ }^{[28]}$

These RSL results are consistent with the data in Table III for the higher levels of cathodic polarization; however, important differences are apparent. In the RSL experiment, $K_{\mathrm{TH}}$ was defined by a resolved load decrease due to crack extension during the static displacement 
hold period. Crack growth during the rising $K$ step was not considered. For highly negative $E_{\mathrm{A}}$ where HEAC is severe, current results show similar $K_{\mathrm{TH}}$ and d $a / \mathrm{d} t$ for the step-load and slow-rising $K$ formats; similar to the RSL data; in both methods $K_{\mathrm{TH}}$ ranges from 12 to $23 \mathrm{MPa} \sqrt{\mathrm{m}}$ below $-1000 \mathrm{mV}_{\mathrm{SCE}}$. The $K_{\mathrm{TH}}$ levels are higher for potentials in the range of -850 to $-700 \mathrm{mV}_{\mathrm{SCE}}$, but the rising $K$ experiments demonstrate $\mathrm{HEAC}$ at $-800 \mathrm{mV}_{\mathrm{SCE}}$ and $K_{\mathrm{TH}}$ of 42 to $44 \mathrm{MPa} \sqrt{\mathrm{m}}$ compared to the RSL implication of immunity for $K$ up to $75 \mathrm{MPa} \vee \mathrm{m} .{ }^{[28]}$ There are two explanations for this difference. First, cracking may have occurred during the RSL test, but was not detected by load decrease if $\mathrm{d} a / \mathrm{d} t$ is low as suggested by the dcPD-based data in Figures 13 and 14. Second, HEAC can be promoted by concurrent plastic strain and $\mathrm{H}$ exposure, characteristic of the slow-rising $K$ protocol, and absent during the RSL hold period. This issue is considered in an ensuing section.

\section{Stable-Ductile Crack Growth}

Aged Monel K-500 is susceptible to unexpected slowstable crack growth below the reported $K_{\mathrm{IC}}$ range (Table II) for three conditions where IG HEAC did not occur. These conditions include: (a) slow-rising $K$ loading in $\mathrm{N}_{2}$, Figure 6; (b) slow-rising $K$ in $\mathrm{NaCl}$ with cathodic polarization more positive than $-750 \mathrm{mV}_{\mathrm{SCE}}$, Figure 14; and (c) the step part of step-hold loading in $\mathrm{NaCl}$ at $-800 \mathrm{mV}_{\mathrm{SCE}}$, Figures 12 and 13. In each case $\mathrm{d} a / \mathrm{d} t$ exceeded the plasticity-based false rate and cracking occurred over a distance which is large compared to the calculated extent of crack tip blunting. Crack extension was TG for each set of conditions and progressed by dimple-based processes. Speculatively by elimination, the growth mechanism is crack tip creep plasticity at ambient temperature and promoted by slow-rising $K$. This suggestion is supported by the: (a) microvoid morphology, (b) lack of IG features, (c) high $K_{\text {IC }}$ (Table II, 198 to $340 \mathrm{MPa} \sqrt{\mathrm{m}}$ ) compared to the lower levels of applied $K_{\mathrm{J}}(<100 \mathrm{MPa} \sqrt{\mathrm{m}})$, (d) lowdiffusible $\mathrm{H}$ concentration of as-received Monel K-500 (Table I heat) below the resolution limit of TDS measurement, and (e) very low $\mathrm{H}$ uptake during stressing in dry $\mathrm{N}_{2}$ or in $\mathrm{NaCl}$ with low crack tip $\eta_{\mathrm{H}}$.

Transgranular creep crack growth is outside the scope of this study, but may be pertinent to long-life damage tolerance of Monel components. Two points are notable. First, faster $\mathrm{d} a / \mathrm{d} t$ for the -700 and $-750 \mathrm{mV}_{\mathrm{SCE}}$ $\mathrm{NaCl}$ cases (Figures 9 and 14) compared to cracking in $\mathrm{N}_{2}$ suggests a lingering role of $\mathrm{H}$ in this plasticity-based environmental cracking. Second, the rate of slow-TG cracking appears to depend on $\mathrm{d} K / \mathrm{d} t$ since $\mathrm{d} a / \mathrm{d} t$ values measured for rising $K$ loading at -700 and $-750 \mathrm{mV}_{\mathrm{SCE}}$ are substantially faster than the very slow rates recorded during the hold periods of the step-hold experiment at $-800 \mathrm{mV}_{\mathrm{SCE}}$ (Figure 12).

\section{Mechanism Informed Modeling of IG HEAC Kinetics}

Model predictions of $K_{\mathrm{TH}}$ and $\mathrm{d} a / \mathrm{d} t$ will strengthen fundamental understanding of HEAC and reduce experimentation required to manage cracking. ${ }^{[13,43,52,72]}$
Intergranular cracking in Monel K-500 stressed in chloride solution at cathodic potentials likely occurs by HEAC. Modeling requires input of the $\mathrm{H}$ concentration on the occluded crack tip surface in equilibrium with the local $\mathrm{H}$ overpotential, plus $\mathrm{H}$ delivered to the FPZ from uptake on bold-exposed surfaces. For Ni alloys, $\mathrm{H}$ production under cathodic polarization is greater on bold-exposed surfaces due to crack tip $\mathrm{pH}$ rise above bulk and less-cathodic crack tip potential from IR difference (Figure 2). ${ }^{[29,54]}$ The decrease in crack tip vs bold surface production of $C_{\mathrm{H} \text {-Diff }}$ is quantified as a function of $E_{\mathrm{A}}$ in Figure 5. However, the intensified 3-dimensional stress state at the crack tip and mid-plane of the SENT specimen dominates HEAC over boldly exposed surface locations. Full-bulk $\mathrm{H}$ charging during a 500,000 second experiment is not likely; the diffusion distance proportional to $2\left(D_{\mathrm{H}} t\right)^{1 / 2}$ is $0.16 \mathrm{~mm}$ for the effective diffusivity of $\mathrm{H}$ in Monel $\mathrm{K}-500\left(1.3 \times 10^{-10} \mathrm{~cm}^{2} / \mathrm{s}^{[29]}\right)$. This H-penetration distance is only 13 pct of the half-thickness of the SENT specimen. In contrast diffusion of crack tip surface $\mathrm{H}$ into the FPZ likely occurs over a very short distance $\left(\sim 1 \mu \mathrm{m}^{[13]}\right)$ dictated by the crack tip stress field. Crack tip $\mathrm{H}$ uptake dominance is supported by SEM observations of uniform IG crack fronts with no preference for enhanced growth near boldly exposed surfaces (Figure 12(a)).

Stress-enhanced crack tip diffusible $\mathrm{H}$ concentration, $C_{\mathrm{H} \sigma}$ given by Eq. [3], is used to predict $K_{\mathrm{TH}}$ (Eq. [1]) and $\mathrm{d} a / \mathrm{d} t_{\mathrm{II}}$ (Eq. [2]) $v s E_{\mathrm{A}}$ for Monel K-500 in $\mathrm{NaCl}$ solution. For applied potentials between -1200 and $-700 \mathrm{mV}_{\mathrm{SCE}}$, the measured-diffusible $\mathrm{H}$ concentrations shown in Figure 4 and elsewhere ${ }^{[29]}$ establish that $C_{\mathrm{L}}$ and $C_{\mathrm{RT}}$ in Eq. [3] are sufficiently low $(<\sim 0.003$ atom fraction $\mathrm{H})$ to justify $\left(1-C_{\mathrm{L}}\right)$ and $\left(1-C_{\mathrm{RT}}\right)$ equaling 1. $E_{\mathrm{B}}$ for $\mathrm{H}$ in aged Monel $\mathrm{K}-500$ is $10.2 \pm 4.4 \mathrm{~kJ} / \mathrm{mol}$, associated with reversible $\mathrm{H}$ trapping at $\mathrm{Ni}_{3} \mathrm{Al}$ precipitates. ${ }^{[29]}$ As such, the exponential binding energy term in Eq. [3] is 55.2 and much greater than 1. With these simplifications Eq. [3] is:

$$
C_{\mathrm{H} \sigma}=\left[\left(1-C_{\mathrm{L} \sigma}\right) \exp \left(\frac{\sigma_{\mathrm{H}} V_{\mathrm{H}}}{\mathrm{RT}}\right)\right]\left[C_{\mathrm{L}} \exp \left(\frac{E_{\mathrm{B}}}{\mathrm{RT}}\right)\right] \text {. }
$$

The value of crack tip $\sigma_{\mathrm{H}}$ used in the ensuing model yields a value of $C_{\mathrm{L} \sigma}$ that is less than 0.050 to 0.10 atom fraction $\mathrm{H}$ for the most negative $E_{\mathrm{A}}$ investigated in the cracking experiments, assuming that $C_{\mathrm{L}}$ is 5 to $10 \mathrm{pct}$ of $C_{\mathrm{H}-\mathrm{Diff}}{ }^{[29]}$ As such, $\left(1-C_{\mathrm{L} \sigma}\right)$ is 0.90 to 0.95 , justifying setting this term equal to 1 . The second-bracketed exponential term in Eq. [10] is $C_{\mathrm{H}-\mathrm{Diff}}$ since $\left(1-C_{\mathrm{L}}\right)$ is also essentially 1 . As such, Eq. [3] demonstrates that $C_{\mathrm{H} \sigma}$ equals the exponential stress enhancement of experimentally determined $C_{\mathrm{H}-\mathrm{Diff}}$, which is established as a function of $E_{\mathrm{A}}$ in Figure 5 and Eq. [9].

\section{E. Threshold for HEAC}

Prediction of the applied potential dependence of the quasi-static $K_{\mathrm{TH}}$ for HEAC utilizes the crack tip micromechanical model by Gerberich et al. ${ }^{[41,81,82]}$ 
(Eq. [11]), based on $\mathrm{H}$ decohesion ${ }^{[83-85]}$ and experimentally validated for a range of steels and a Ni-based superalloy. ${ }^{[42,43,82]}$ The premise of this model is that near-crack-tip stress (and local stress intensity) is modeled by coupling a small array of dislocations, spaced in equilibrium with the crack tip elastic stress field, and including Rice-Thompson dislocation emission. ${ }^{[86]}$ These dislocations shield the singular-elastic stress at the crack tip. Surrounding-tip plasticity is represented by a superdislocation located at the centroid of the highly strained continuum plastic zone, and related to stress intensity. ${ }^{[44,81,82]}$ Crack tip stress of order 16 to $25 \mathrm{GPa}$ is predicted for $\mathrm{Fe}-\mathrm{Si}$ and $\mathrm{Mo},{ }^{[44]}$ and is maximum at 20 to $100 \mathrm{~nm}$ ahead of the crack tip surface. This estimate is consistent with Oriani's original decohesion model. ${ }^{[83]}$ Gerberich et al.$^{[82]}$ validated the crack tip dislocation-based model by showing that the $\mathrm{H}_{2}$ pressure dependence of $k_{\mathrm{IH}}$ (equal to $\left(k_{\mathrm{IG}}-\alpha C_{\mathrm{H} \sigma}\right)$ ) for a steel is consistent with the measured $\mathrm{H}_{2}$ pressure dependence of the surface energy of iron (equal to $k_{\mathrm{IH}}^{2} / 2 \mathrm{E}$ according to the Griffith theory). Such data are not available for $\mathrm{Ni}$ or a superalloy.

Uncertain crack tip $\sigma_{\mathrm{H}}$ is a persisting issue in HEAC modeling. The value of $\sigma_{\mathrm{H}} / \sigma_{\mathrm{YS}}$ used in Eq. [3] does not affect the ability of this approach to predict the $E_{\mathrm{A}}$ dependence of $K_{\mathrm{TH}}$ since $\sigma_{\mathrm{H}} / \sigma_{\mathrm{YS}}$ inversely scales with the adjustable parameter, $\alpha$, in Eq. [1]. The discrete dislocation model (maximum hydrostatic stress $\sim 20 \sigma_{\mathrm{YS}}$ at 20 to $100 \mathrm{~nm}$ beneath the crack tip $)^{[41,81,82]}$ and a blunted crack finite element model (maximum hydrostatic stress 3 to $5 \sigma_{\mathrm{YS}}$ at 2 to $\left.5 \mu \mathrm{m}\right)^{[52,53]}$ bound the crack tip stress field relevant for HEAC modeling. This latter hydrostatic stress may be increased if strain gradient plasticity impacts the crack tip stress distribution. ${ }^{[47,87]}$ Moreover, TEM of the deformed crack wake in $\mathrm{Ni}$ and $\mathrm{Fe}$ shows that $\mathrm{H}$ promotes a dislocation cell structure that could provide increased crack tip stresses from work hardening to favor decohesion. ${ }^{[38,88-90]}$ Based on these considerations, $\sigma_{\mathrm{H}} / \sigma_{\mathrm{YS}}$ was assumed to equal 12.0. The values of $\alpha^{\prime \prime}(0.00018 \mathrm{MPa} \mathrm{m})$ and $\beta^{\prime}(0.26 /$ $\mathrm{MPa} \sqrt{ } \mathrm{m})$ in Eq. [1] were established by analytical approximation to the dislocation simulations of the near-crack-tip stress field, ${ }^{[41,81,82]}$ and validated by experiment. $^{[43]}$ The intrinsic Griffith toughness of the IG interface without $\mathrm{H}, k_{\mathrm{IG}}$, is not physically related to $K_{\text {IC }}$ for microvoid fracture $(198$ to $340 \mathrm{MPa} \sqrt{\mathrm{m}}$; Table II) or to the $K$ levels that caused TG creep crack growth in Monel K-500 (60 to $80 \mathrm{MPa} \sqrt{\mathrm{m}}$, Figure 6). Rather, $k_{\mathrm{IG}}$ was equated to $0.675 \mathrm{MPa} \sqrt{\mathrm{m}}$ so as to predict $K_{\mathrm{TH}}$ of $100 \mathrm{MPa} \sqrt{\mathrm{m}}$ when $C_{\mathrm{H} \text {-Diff }}=0$. This is a reasonable-lower bound since IG cracking was not observed for $K_{\mathrm{J}}$ up to this value for $E_{\mathrm{A}}$ that produced $C_{\text {H-Diff }}$ near 0 . The $\alpha$ was set to $0.56(\mathrm{MPa} \sqrt{\mathrm{m}}$ per atom fraction $\mathrm{H}$ ) to fit the model to the average of three $K_{\mathrm{TH}}$ values $(18.0 \mathrm{MPa} \sqrt{\mathrm{m}})$ measured at $E_{\mathrm{A}}$ of $-1000 \mathrm{mV}$ SCE.

With these input parameters, Figure 15 demonstrates that Eq. [1] predicts the dependence of $K_{\mathrm{TH}}$ on the fundamentally important stress-enhanced concentration of $\mathrm{H}$ in the crack tip FPZ ( $C_{\mathrm{H} \sigma}$, top axis), as well as on the $C_{\mathrm{H} \text {-Diff }}$ associated with the occluded crack tip $\eta_{\mathrm{H}}$ (bottom axis). Predicted and measured $K_{\mathrm{TH}}$ agree, and each decreases strongly with initial increase in $C_{\mathrm{H}-\mathrm{Diff}}$

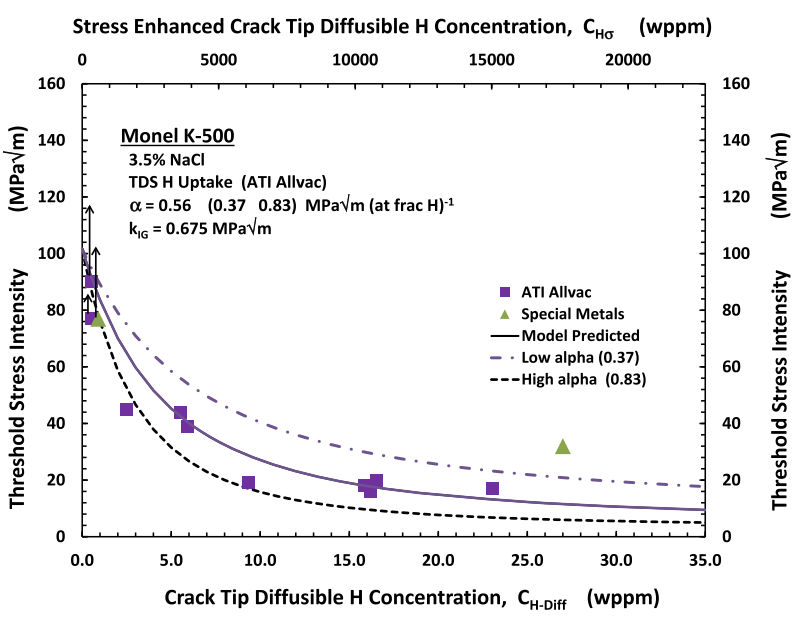

Fig. 15-(Color online) Model predicted (Eq. [1]) and measured (Table III) $K_{\mathrm{TH}} v s$ occluded crack tip $C_{\mathrm{H}-\mathrm{Diff}}$ (bottom axis) and stressenhanced $C_{\mathrm{H} \sigma}$ (top axis) for aged Monel K-500 (ATI Allvac, $\mathbf{\square}$; Table I) stressed in 3.5 pct $\mathrm{NaCl}$ at $E_{\mathrm{A}}$ between -1100 and $-700 \mathrm{mV}_{\mathrm{SCE}}$. The relationship between $C_{\mathrm{H}-\mathrm{Diff}}$ and applied potential is given by Eq. [9] and $\sigma_{\mathrm{H}} / \sigma_{\mathrm{YS}}$ equals 12.0 in Eq. [3]. Measured $K_{\mathrm{TH}}$ are included for a second lot of aged Monel K-500 (Special Metals, $\boldsymbol{\Lambda}$; Footnote *) using the corresponding $\mathrm{H}$ uptake law (Footnote **).

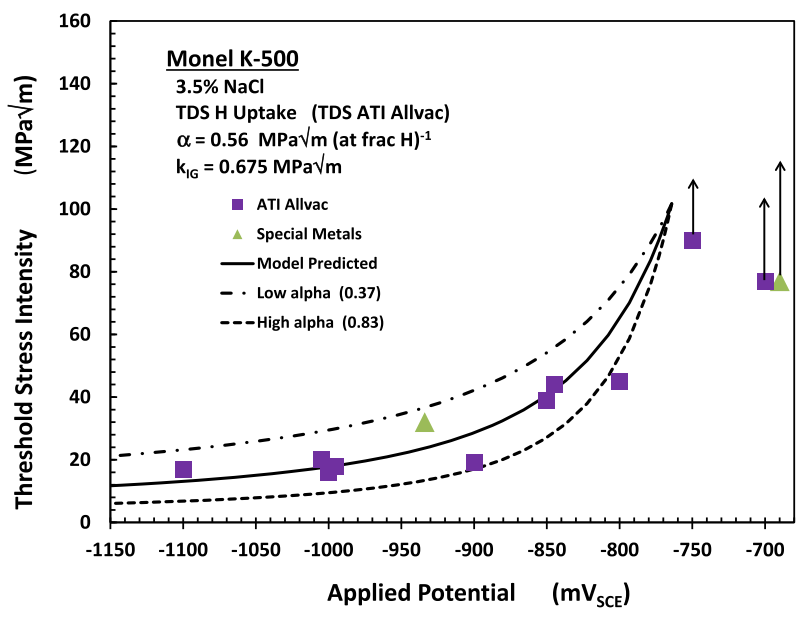

Fig. 16-(Color online) Model predicted (Eq. [1]) and measured (Table III) $K_{\mathrm{TH}}$ for HEAC vs $E_{\mathrm{A}}$ for aged Monel K-500 (ATI Allvac, $\mathbf{\square}$; Table I) stressed in 3.5 pet NaCl. The $\sigma_{\mathrm{H}} / \sigma_{\mathrm{YS}}$ is 12.0 in Eq. [3]. Measured $K_{\mathrm{TH}}$ are included for a second lot of aged Monel K-500 (Special Metals, $\mathbf{\Delta}$; Footnote *).

(and $C_{\mathrm{H} \sigma}$ ) to reach a lower limit at high $\mathrm{H}$ concentrations. The model also successfully predicts the strong dependence of $K_{\mathrm{TH}}$ on applied potential, as shown in Figure 16. Figure 5 and Eq. [9] show that crack tip $C_{\mathrm{H} \text {-Diff }}$ extrapolates to 0 at an applied potential of $-764 \mathrm{mV}_{\mathrm{SCE}}$. The model predictions in Figure 16 show that $K_{\mathrm{TH}}$ approaches the $\mathrm{H}$-free toughness at this level of $E_{\mathrm{A}}$ and associated $C_{\mathrm{H}-\mathrm{Diff}}$ of 0 . Experiments (Figures 9 through 11) established that HEAC occurred at $-800 \mathrm{mV}_{\mathrm{SCE}}$, but not at -750 or $-700 \mathrm{mV}_{\mathrm{SCE}}$. The impact of a 50 pct higher $\alpha(0.83 \mathrm{MPa} \sqrt{\mathrm{m}}$ per atom fraction $\mathrm{H})$, and 50 pet lower $\alpha(0.37 \mathrm{MPa} \sqrt{\mathrm{m}}$ per atom fraction $\mathrm{H}$ ), is shown by the dashed lines in Figures 15 and 16 with other parameters held constant. 
The values of the parameters used for the fits shown in Figures 15 and 16 are justified based on previous applications of this model and in the previous paragraphs. The precise $k_{\mathrm{IG}}$ used for grain boundary "brittle fracture" is important, but the choice does not affect the conclusion that the $K_{\mathrm{TH}}$ model is validated. As an example, $k_{\mathrm{IG}}$ of $0.72 \mathrm{MPa} \sqrt{\mathrm{m}}$ corresponds to a macroscopic interface toughness of $160 \mathrm{MPa} \sqrt{\mathrm{m}}$. An $\alpha$ of $0.68 \mathrm{MPa} \sqrt{\mathrm{m}}$ per atom fraction $\mathrm{H}$, with this higher $k_{\mathrm{IG}}$, provides a similar-good fit to the experimental data as that shown in Figures 15 and 16. The precise crack tip stress distribution and associated $\mathrm{H}$ trapping (Eq. [3]) does not alter the conclusion that the present approach predicts the $E_{\mathrm{A}}$ dependence of $K_{\mathrm{TH}}$. The good fits shown in Figures 15 and 16 are preserved if the blunted crack tip value of $\sigma_{\mathrm{H}} / \sigma_{\mathrm{YS}}$ of 4.0 is employed in place of $\sigma_{\mathrm{H}} / \sigma_{\mathrm{YS}}$ equaling 12.0 to estimate $C_{\mathrm{H} \sigma}$ through Eq. [3]. ${ }^{[52]}$ The corresponding best fit $\alpha$ is $26.2 \mathrm{MPa} \sqrt{\mathrm{m}}$ per atom fraction $\mathrm{H}$, calibrated by measured $K_{\mathrm{TH}}$ for $E_{\mathrm{A}}$ of $-1000 \mathrm{mV} \mathrm{V}_{\mathrm{SCE}}$. The higher $\sigma_{\mathrm{H}} / \sigma_{\mathrm{YS}}$ of 12.0 calculation is favored as consistent with the discrete dislocation basis of $\mathrm{Eq}_{\text {. }}[1]^{[41]}$ and local dislocation structure hardening. ${ }^{[38,88-90]}$

Modeling of $K_{\mathrm{TH}} v s$ applied potential depends on the input values of crack tip $C_{\mathrm{H}-\mathrm{Diff}}$ vs $E_{\mathrm{A}}$ (Figure 5 and Eq. [9]). It is uncertain as to whether crack tip H uptake is determined by $x^{2} / G$ scaling, as done for the modeling in Figures 15 and 16, or by $x / G$ scaling; however, the former dependence is justified. ${ }^{[54]}$ If crack chemistry and $\mathrm{H}$ uptake are governed by $x / G$, then the relationship between crack tip $C_{\mathrm{H}-\mathrm{Diff}}$ and $E_{\mathrm{A}}$ given by the dashed line in Figure 5 and Eq. [9] shifts to a lower $\mathrm{H}$ concentration at each $E_{\mathrm{A}}$. The absolute value of this concentration reduction is about a factor of 2 based on $x / G$ correlation over the relevant range from 90 to 200 . Identically good agreement between model predicted and measured $K_{\mathrm{TH}}$ (Figures 15 and 16) is achieved by raising the fitting parameter, $\alpha$, in direct proportion to this lowering of $C_{\mathrm{H} \text {-Diff }}$ such that $\alpha C_{\mathrm{H} \sigma}$ is constant, as shown by Eqs. [1] and [3]. Similarly, the planar electrode $C_{\mathrm{H}-\text { Diff }}$ dependence on $E_{\mathrm{A}}$ depends on the method used for $\mathrm{H}$ analysis (Figure 4). For this study and a separate investigation of a different lot of Monel K-500, ${ }^{[29]}$ diffusible $\mathrm{H}$ concentration from the barnacle cell measurement was consistently less than that from hot extraction-calibrated TDS. This reduction factor is 3.4 at $-1000 \mathrm{mV}_{\mathrm{SCE}}$ for the data in Figure 4 and 4.7 for the previous study. ${ }^{[29]}$ If this difference is constant at each potential in Figure 4, then use of the barnacle cell-based $\mathrm{H}$ uptake dependence on $E_{\mathrm{A}}$ will not affect the quality of predicted vs measured $K_{\mathrm{TH}}$ in Figures 15 and 16 . However, the absolute value of $\alpha$ necessary to fit the data at $E_{\mathrm{A}}$ of $-1000 \mathrm{mV}_{\mathrm{SCE}}$ rises inversely with decreasing planar electrode $C_{\mathrm{H} \text {-Diff. }}$.

HEAC in a second lot of Monel K-500 (Footnote *) is represented $(\mathbf{\Delta})$ in Figures 15 and $16 . K_{\mathrm{TH}}$ for this alloy was very high at $-700 \mathrm{mV}_{\mathrm{SCE}}$, consistent with the fall in $C_{\mathrm{H}-\mathrm{Diff}}$ to 0 near this potential. For each lot of Monel K-500, measured and model predicted $K_{\mathrm{TH}}$ agree when plotted vs $E_{\mathrm{A}}$ (Figure 16); however, this is misleading. The $C_{\text {H-Diff }}$ is consistently 2.3 times higher in the second lot of Monel K-500 for a given applied potential (Footnote $* *[29]$ ) compared to the heat studied in the present work (Table III). Comparison based on $E_{\mathrm{A}}$, is therefore not a fundamentally correct way to view the behavior of these two lots of Monel K-500 since crack tip diffusible $\mathrm{H}$ varies. The comparison in Figure 15 includes the correct $\mathrm{H}$ uptake law for the ATI Allvac lot (Figure 4) and the Special Metals lot (Footnote **) in the calculation of crack tip $C_{\text {H-Diff. }}$ On this correct basis, the two lots of Monel K-500 are not well described by a single set of model constants. The trend in Figure 15 for $\alpha=0.56 \mathrm{MPa} \sqrt{\mathrm{m}}$ per atom fraction $\mathrm{H}$ is shifted to intersect the two values of $K_{\mathrm{TH}}(\boldsymbol{\Delta})$ for the Special Metals lot of Monel K-500 by changing $\alpha$ to $=0.27$ $\mathrm{MPa} \sqrt{\mathrm{m}}$ per atom fraction $\mathrm{H}$ for $k_{\mathrm{IG}}=0.675 \mathrm{MPa} \sqrt{\mathrm{m}}$. This difference in $\alpha$ implies that these two lots of Monel K-500 are intergranularly embrittled to a different extent by the same $C_{\mathrm{H} \sigma}$, suggesting a metallurgical effect on HEAC. This speculation, or a parallel explanation quantified by alloy-sensitive change in $k_{\mathrm{IG}}$, must be verified and the governing microstructure-composition factor(s) identified.

Good agreement between measured and model predicted dependencies of $K_{\mathrm{TH}}$ on applied potential supports the conclusion that a critical level of cathodic polarization must be exceeded before HEAC can progress at a significant rate in Monel K-500 stressed in NaCl. With a single-calibration parameter, $\alpha$, the model quantitatively captures the $E_{\mathrm{A}}$ dependence of $K_{\mathrm{TH}}$ in spite of uncertainties associated with crack tip stress and $H$ uptake. Refinement of either factor only changes the absolute value of $\alpha$, which is a weighting parameter that quantifies the sensitivity of a grain boundary to decohesion for a given $C_{\mathrm{H} \sigma}$. The $\alpha$ that governs HEAC should depend on metallurgical factors such as boundary chemistry, structure, and slip interaction. The absolute value of $\alpha$ is important if this factor is interpreted based on a first principles model of boundary- $\mathrm{H}$ decohesion.

\section{F. Stage II Crack Growth Rate}

Knowing the relationship between $E_{\mathrm{A}}$ and crack tip diffusible $\mathrm{H}$ concentration $\left(C_{\mathrm{H} \text {-Diff }}\right.$ scaled to $\left.C_{\mathrm{H} \sigma}\right)$, it is possible to predict the $E_{\mathrm{A}}$ dependence of $\mathrm{d} a / \mathrm{d} t_{\mathrm{II}}$ based on HEAC rate limited by $\mathrm{H}$ diffusion in the FPZ. ${ }^{[45]}$ Equation [2] predicts $\mathrm{d} a / \mathrm{d} t_{\mathrm{II}}$ using a single adjustable parameter, $C_{\mathrm{H} \sigma \text {-crit }}$, with all other terms in this model independently known. The $D_{\mathrm{H}}$ for $\mathrm{H}$ in aged Monel K-500 at $298 \mathrm{~K}\left(25^{\circ} \mathrm{C}\right)$ was reported as $5 \times 10^{-11} \mathrm{~cm}^{2} / \mathrm{s}$, ${ }^{[4]}$ 1.5 to $1.9 \times 10^{-10} \mathrm{~cm}^{2} / \mathrm{s},{ }^{[24]}$ and $9 \times 10^{-11}$ to $4 \times 10^{-10} \mathrm{~cm}^{2} / \mathrm{s}^{[29]}$; a $\mathrm{H}$ diffusivity of $1 \times 10^{-10} \mathrm{~cm}^{2} / \mathrm{s}$ is used. The applied potential dependence of $C_{\mathrm{H}-\mathrm{Diff}}$ for $x^{2} / \mathrm{G}$ relevant to an SENT crack is given in Figure 5 and Eq. [9] for ATI Allvac Monel K-500. The $x_{\text {crit }}$ in Eq. [2] is $1 \mu \mathrm{m}$ for HEAC in a wide range of high strength alloys. ${ }^{[43,45]}$ The crack tip $\sigma_{\mathrm{H}}$ in Eq. [3] is assumed to be $12 \sigma_{\mathrm{YS}}$, consistent with $x_{\text {crit }}$ of 100 to $1000 \mathrm{~nm}$ as justified for the $K_{\mathrm{TH}}$ model.

Model predictions of Stage II crack growth rate are presented in Figures 17 and 18, using an adjustable best fit $C_{\mathrm{H} \sigma \text {-crit }}$ of 1100 wppm. Predicted and measured (Table III) $\mathrm{d} a / \mathrm{d} t_{\mathrm{II}}$ agree when considered as a function of either crack tip diffusible $\mathrm{H}$ concentration (Figure 17, bottom axis), 
stress-enhanced concentration of $\mathrm{H}$ at the crack tip $\left(C_{\mathrm{H} \sigma}\right.$, top axis) or applied cathodic potential (Figure 18$) .{ }^{\S}$

\begin{abstract}
${ }^{\S}$ Measured $\mathrm{d} a / \mathrm{d} t_{\mathrm{II}}$ values in Figures 17 and 18 include results for the Special Metals lot of aged Monel K-500 (Footnote*, $\boldsymbol{\Delta}$ ). The modified $\mathrm{H}$ uptake relationship (Footnote ${ }^{* *}$ ) was used to define $C_{\mathrm{H} \sigma}$ so the prediction in Figure 17 is valid. The good agreement with the $\mathrm{d} a / \mathrm{d} t_{\mathrm{II}}$ model prediction in Figure 18 is due to the predicted insensitivity of $\mathrm{d} a / \mathrm{d} t_{\mathrm{II}}$ to the 2.3 times higher $C_{\mathrm{H}-\mathrm{Diff}}$ for the Special Metals alloy at a given $E_{\mathrm{A}}$.
\end{abstract}

The fastest Stage II crack growth rate measured at $E_{\mathrm{A}}$ of $-1100 \mathrm{mV}_{\mathrm{SCE}}, 0.17 \mu \mathrm{m} / \mathrm{s}$, agrees with Eq. [2] when $C_{\mathrm{H} \sigma} \gg C_{\mathrm{H} \sigma \text {-crit }}$, and this model suggests that more severe cathodic polarization will only cause a small-additional increase in $\mathrm{d} a / \mathrm{d} t_{\mathrm{II}}$. Specifically, the squared inverse error function term in Eq. [2] equals 1.04 when $C_{\mathrm{H} \sigma}=7 C_{\mathrm{H} \sigma \text {-crit }}$ $(7700 \mathrm{wppm} \quad \mathrm{H})$ and 4.8 when $C_{\mathrm{H} \sigma}=500 C_{\mathrm{H} \sigma \text {-crit }}$ $(550,000$ wppm $\mathrm{H})$. For this range of $C_{\mathrm{H} \sigma} / C_{\mathrm{H} \sigma \text {-crit }}$, the predicted Stage II crack growth rate from Eq. [2] equals 4.2 to 19.2 times $\left(D_{\mathrm{H}} / x_{\text {crit }}\right)$, or 0.04 to $0.19 \mu \mathrm{m} / \mathrm{s}$ for $D_{\mathrm{H}}$ of $1.0 \times 10^{-10} \mathrm{~cm}^{2} / \mathrm{s}$.

Good agreement between measured and modeled $\mathrm{d} a$ / $\mathrm{d} t_{\mathrm{II}}$ affirms the validity of HEAC in Monel K-500 as rate limited by $\mathrm{H}$ diffusion within the $1 \mu \mathrm{m}$ crack tip FPZ. This model prediction relies on a single-calibration parameter, $C_{\mathrm{H} \sigma \text {-crit }}$, which is referenced in the context of $C_{\mathrm{H} \sigma}$ governed by occluded crack tip $\eta_{\mathrm{H}}$ and crack tip hydrostatic stress enhancement. The squared inverse error function of the concentration term of $\left(1-C_{\mathrm{H} \sigma \text {-crit }}\right) / C_{\mathrm{H} \sigma}$ dictates the shallow decrease in $\mathrm{d} a / \mathrm{d} t_{\text {II }}$ with decreasing $\mathrm{H}$ concentration (increasing $E_{\mathrm{A}}$ ). The somewhat steeper decline in measured growth rates may be speculatively explained by a modest decrease of $D_{\mathrm{H}}$ with decreasing $C_{\mathrm{H} \text {-Diff }}$ (increasing $E_{\mathrm{A}}$ ) due to reversible $\mathrm{H}$ trapping at dislocations or $\gamma^{\prime} .^{[50]}$ The model prediction in Figures 17 and 18 used a constant $D_{\mathrm{H}}$. The inverse error function term also controls the technologically important potential dependence of $\mathrm{d} a / \mathrm{d} t_{\mathrm{II}}$

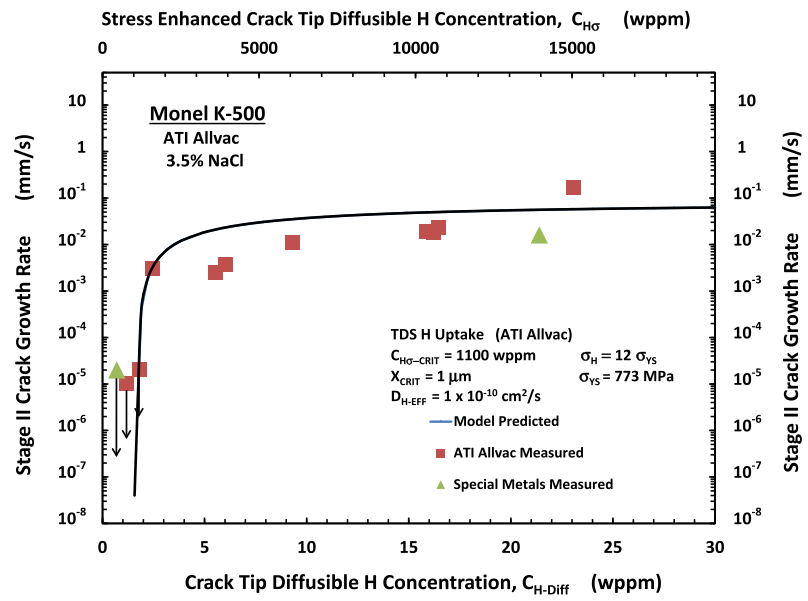

Fig. 17-(Color online) Model predicted (Eq. [2]) and measured Stage II crack growth rate (at elastic $K=50 \mathrm{MPa} \sqrt{\mathrm{m}}$; Table III; Fig. 9) $v s$ crack tip $C_{\mathrm{H}-\mathrm{Diff}}$ (bottom axis) and stress-enhanced $C_{\mathrm{H} \sigma}$ (top axis) for aged Monel K-500 (ATI Allvac, $\mathbf{\square}$; Table I) stressed in 3.5 pet $\mathrm{NaCl}$ at $E_{\mathrm{A}}$ between -1100 and $-700 \mathrm{mV}_{\mathrm{SCE}}$. The $\sigma_{\mathrm{H}} / \sigma_{\mathrm{YS}}$ is 12.0 in Eq. [3]. Measured $\mathrm{d} a / \mathrm{d} t_{\mathrm{II}}$ are included for a Special Metals lot of Monel K-500 ( $\mathbf{\Delta})$ using the corresponding $\mathrm{H}$ uptake law (Footnotes $*$ and ${ }^{* *}$ ). where growth rate plummets with further small rise in applied potential above a critical value. This sharp reduction in $\mathrm{d} a / \mathrm{d} t_{\mathrm{II}}$ is accompanied by a transition from IG HEAC (at $-800 \mathrm{mV}_{\mathrm{SCE}}$, Figure 10) to ductile cracking (at -750 and $-700 \mathrm{mV} V_{\mathrm{SCE}}$, Figure 11). For the parameters employed and $C_{\mathrm{H} \sigma \text {-crit }}=1100 \mathrm{wppm}$, this severe drop-off in HEAC $\mathrm{d} a / \mathrm{d} t_{\mathrm{II}}$ is predicted to occur at $E_{\mathrm{A}}$ above $-810 \mathrm{mV}_{\mathrm{SCE}}$, in excellent agreement with the measurements in Table III. Specifically, for increasing $E_{\mathrm{A}}$ from -810 to $-787 \mathrm{mV}_{\mathrm{SCE}}$ in Figure 18 , crack tip $C_{\mathrm{H}-\mathrm{Diff}}$ falls from 3.2 to $1.6 \mathrm{wppm}\left(C_{\mathrm{H} \sigma}\right.$ falls from 2060 to $1023 \mathrm{wppm}$, Figure 17 for $\left.\sigma_{\mathrm{H}} / \sigma_{\mathrm{YS}}=12.0\right)$ and the squared inverse error function term in Eq. [2] decreases from 0.19 to $5 \times 10^{-7}$. This concentration term in the diffusion model causes the predicted seven order of magnitude decrease in $\mathrm{d} a / \mathrm{d} t_{\mathrm{II}}$ for a $23 \mathrm{mV}$ increase in $E_{\mathrm{A}}$. Experiments established that IG HEAC was produced at $-800 \mathrm{mV}_{\mathrm{SCE}}$ (Figure 10) with the rate plotted in the upper plateau of Figures 17 and 18. SEM analysis did not resolve HEAC for the experiments at either -750 or $-700 \mathrm{mV}_{\mathrm{SCE}}$ and for $K_{\mathrm{J}}$ up to $80 \mathrm{MPa} \sqrt{\mathrm{m}}$ (Figure 14 ).

The specific value of $C_{\mathrm{H} \sigma \text {-crit }}$ affects the predicted potential for the strong decrease in $\mathrm{d} a / \mathrm{d} t_{\mathrm{II}}$, but not the maximum $\mathrm{d} a / \mathrm{d} t_{\text {II }}$ which is achieved at more negative potentials. Model sensitivity analysis provides the critical levels of $E_{\mathrm{A}}$ necessary to eliminate HEAC for various assumed $C_{\mathrm{H} \sigma \text {-crit }}$ values: $275 \mathrm{wppm}$ and $-770 \mathrm{mV}_{\mathrm{SCE}}$, $550 \mathrm{wppm}$ and $-777 \mathrm{mV}_{\mathrm{SCE}}, \quad 1100 \mathrm{wppm}$ and $-787 \mathrm{mV}_{\mathrm{SCE}}$ (Figure 18), $2200 \mathrm{wppm}$ and $-814 \mathrm{mV}_{\mathrm{SCE}}$, $4400 \mathrm{wppm}$ and $-865 \mathrm{mV}_{\mathrm{SCE}}$, and $6600 \mathrm{wppm}$ and $-910 \mathrm{mV}_{\mathrm{SCE}}$. Steep reductions in $\mathrm{d} a / \mathrm{d} t_{\mathrm{II}}$ are predicted for this wide range of assumed $C_{\mathrm{H} \sigma \text {-crit }} \cdot{ }^{\$}$ This analysis

\footnotetext{
${ }^{\S}$ Listed values of $C_{\mathrm{H} \sigma \text {-crit }}$ are relative to $C_{\mathrm{H} \sigma}$ which was stress enhanced by a factor of 650 (Eq. [3]) for Monel K-500 with $\sigma_{\mathrm{YS}}=773 \mathrm{MPa}$ and $\sigma_{\mathrm{H}}=12 \sigma_{\mathrm{YS}}$. In the context of stress-free $C_{\mathrm{H}-\mathrm{Diff}}$, critical $\mathrm{H}$ concentrations for $\mathrm{d} a / \mathrm{d} t_{\mathrm{II}}$ falloff vary from 10.1 to $0.4 \mathrm{wppm}$ for this sensitivity analysis.
}

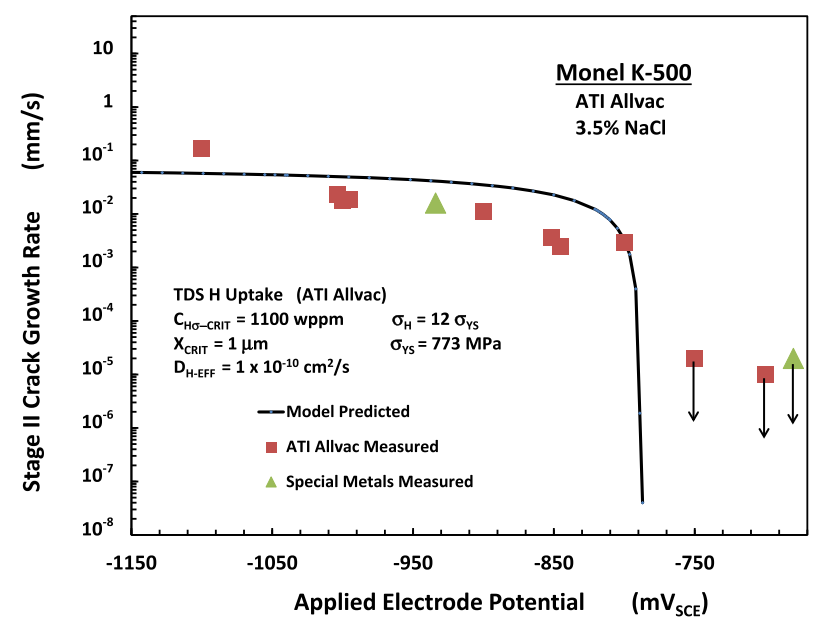

Fig. 18-(Color online) Model predicted (Eq. [2]) and measured Stage II crack growth rate (at elastic $K=50 \mathrm{MPa} \sqrt{\mathrm{m}}$; Table III; Fig. 9) $v s$ applied cathodic potential for aged Monel K-500 (ATI Allvac, - ; Table I) stressed in $3.5 \mathrm{pct} \mathrm{NaCl}$. The $\sigma_{\mathrm{H}} / \sigma_{\mathrm{YS}}$ equals 12.0 in Eq. [3]. Measured $\mathrm{d} a / \mathrm{d} t_{\mathrm{II}}$ values are included for a Special Metals lot of Monel K-500 (Footnote *, $\mathbf{\Lambda}$ ). 
supports the expectation that HEAC occurs when applied cathodic polarization is more negative than a potential in the range of -770 to $-900 \mathrm{mV}_{\mathrm{SCE}}$. The precise potential may depend on subtle differences in Monel metallurgy effects on $C_{\mathrm{H} \sigma \text {-crit }}$ and the $\mathrm{H}$ uptake law. This variation in critical potential, coupled with the conservative characterization of HEAC resistance provided by the slow-rising $K$ method (discussed in the next section), are important considerations when predicting IG EAC in a component.

\section{G. Effect of Loading Protocol}

The results for HEAC in Monel K-500 suggest a strong effect of loading protocol, depending on applied potential. Similar rates of IG HEAC were produced for slowrising $K$ and quasi-static $K$ loading, but only when cracking was relatively severe at $E_{\mathrm{A}}$ below about $-900 \mathrm{mV}_{\text {SCE}}$. These kinetics of IG HEAC are governed by applied $K$, and the associated crack tip stress and strain fields, independent of crack growth or $K$ history. In contrast for milder cathodic polarization $\left(E_{\mathrm{A}}\right.$ above -900 to $-800 \mathrm{mV}_{\mathrm{SCE}}$ ) and lower $C_{\mathrm{H} \text {-Diff, }}$ IG HEAC occurred for slow-rising stress intensity loading with a substantial amount of TG cracking present (Figure 10). However, $\mathrm{d} a / \mathrm{d} t$ was near-zero (Figure 13) for constant $K$ during a hold period after a fast-step rise in $K$ and IG HEAC was eliminated (Figure 12). A similar result was reported for HEAC in IN718 ${ }^{[14]}$ For alloys in aqueous environments, the damaging effect of slow-rising $K$ may be ascribed to the effect of crack tip strain and strain rate on crack surface film stability and reactivity leading to increased $\mathrm{H}$ uptake. ${ }^{[75,91]}$ Slow-rising $K$ similarly lowered the threshold for hydrogen embrittlement of steel, either stressed in pure $\mathrm{H}_{2},{ }^{[49]}$ or precharged with $\mathrm{H}$ then stressed in air. ${ }^{[13]}$ For these cases, the different behavior of a stationary crack under rising $K v s$ a propagating crack under fixed or falling $K$ is related to interaction of FPZ stress, plastic strain, and trapped $\mathrm{H}$ leading to "plasticity-related hydrogen induced cracking" (PRHIC). ${ }^{[49,92,93]}$

It is not possible to establish the cause of the loading format effect on HEAC of Monel K-500. A role of crack tip plasticity is suggested by slip traces on grain facets (Figure 8), as well as by Transmission Electron Microscopy (TEM) observations of $\mathrm{H}$-affected crack tip dislocation structure in $\mathrm{Ni}^{[38]}$ Speculatively, highly localized slip, perhaps intensified by $\mathrm{H}$ interaction with moving dislocations, ${ }^{[94,95]}$ impacts grain boundaries during strain accumulation. This plasticity could promote grain boundary decohesion by providing microscopic stress concentration and $\mathrm{H}$ enrichment at dislocation-generated trap sites including: altered grain boundary structure, ${ }^{[38]}$ adjacent cell interface structure, ${ }^{[89,90,96]}$ plasticity-boundary carbide interaction, ${ }^{[97]}$ or grain boundary microvoids. ${ }^{[98,99]}$ Moreover, as $E_{\mathrm{A}}$ becomes more positive above about $-900 \mathrm{mV}_{\mathrm{SCE}}$, TG HEAC occurs and may involve $\mathrm{H}$ damage associated with slip band and twin band intersections. ${ }^{[1,100]}$ PRHIC in steels ${ }^{[13,49]}$ and $\mathrm{Ni}$ alloys appears to be most severe (lowest-intrinsic $K_{\mathrm{TH}}$ and fastest $\mathrm{d} a / \mathrm{d} t$ ) when crack tip strain and crack tip $\mathrm{H}$ accumulate concurrently. Cracking is less severe when plastic strain accumulates before $\mathrm{H}$ exposure, or when crack propagation during $\mathrm{H}$ exposure lowers the severity of the crack tip strain field. ${ }^{[4]}$ These concepts are used to examine the loading format effect on HEAC in Monel K-500. The approach taken is based on blunt-crack continuum mechanics and plastic strain-based failure, rather than the decohesion-based models of $K_{\mathrm{TH}}$ and $\mathrm{d} a / \mathrm{d} t_{\mathrm{II}}$ used for higher $C_{\mathrm{H}-\mathrm{Diff}}($ Figures 15 through 18).

The ratio of $K_{\mathrm{TH}}$ for the onset of HEAC under slowrising $K\left(K_{\mathrm{THi}}\right)$ to the threshold for crack arrest $\left(K_{\mathrm{THa}}\right)$ during propagation under falling $K$ appears to provide an indicator of the importance of loading format. Continuum analysis of the effect of crack propagation on the strength of the crack tip strain singularity yielded ${ }^{[49]}$ :

$$
\frac{K_{\mathrm{THa}}}{K_{\mathrm{THi}}}=\left(A^{\prime}\right) \frac{\left[\exp \left(\varepsilon_{\mathrm{f}}^{\mathrm{H}} / \varepsilon_{\mathrm{o}}\right)\right]^{B}}{\sqrt{\left(\varepsilon_{\mathrm{f}}^{\mathrm{H}} / \varepsilon_{\mathrm{o}}\right)}},
$$

where $\varepsilon_{\mathrm{f}}^{\mathrm{H}}$ is the $\mathrm{H}$-sensitive crack-tip effective-plastic strain at fracture, $\varepsilon_{\mathrm{O}}$ is yield strain $(0.004$ for $\mathrm{H}$-free Monel K-500), and $A^{\prime}(\sqrt{ } \pi)$ and $B(0.3)$ are constants from analysis of an elastic-perfectly plastic solid. ${ }^{[101]}$ While this model centers on critical strain, the $\mathrm{H}$ damage mechanism can involve stress controlled interface decohesion with local fracture stress directly related to $\varepsilon_{\mathrm{f}}^{\mathrm{H}}$. For HEAC in IN718, $\varepsilon_{\mathrm{f}}^{\mathrm{H}}$ was experimentally determined using locally measured dimple size in two void growth models, then correlated with occluded crack $C_{\text {H-total }}$, each as a function of bulk solution $\mathrm{pH}^{\left[{ }^{[14]}\right.}$ Specifically, $\varepsilon_{\mathrm{f}}^{\mathrm{H}}$ decreases monotonically with increasing $\mathrm{H}$ concentration:

$$
\sqrt{\varepsilon_{\mathrm{f}}^{\mathrm{H}}}=\left(0.19-2.38 \times 10^{-3} C_{\mathrm{H}-\text { total }}\right),
$$

where $C_{\text {H-total }}$ (wppm, over the range from 0 to $40 \mathrm{wppm}$ ) was estimated as the value in equilibrium with crack tip $\mathrm{pH}$ and potential, but not stress-enhanced analogous to Eq. [9] for Monel K-500. A similar result was reported for $\mathrm{H}$ cracking of IN903. ${ }^{[100]}$ A loading format effect on HEAC is expected when $K_{\mathrm{THa}} / K_{\mathrm{THi}}$ (Eq. [11]) exceeds unity, as is likely when $\varepsilon_{\mathrm{f}}^{\mathrm{H}}$ (Eq. [12]) rises due to increasing $\mathrm{H}$-free alloy ductility or reduced $\mathrm{H}$ uptake.

Equations [11] and [12] provide the basis to interpret the observed loading format effect on HEAC in Monel $\mathrm{K}-500$ stressed in $\mathrm{NaCl}$. Equation [9] shows that $C_{\mathrm{H}-\mathrm{Diff}}$ falls from 23 to $2.5 \mathrm{wppm}$ for $-1100 \mathrm{mV}_{\mathrm{SCE}}$ $<E_{\mathrm{A}}<-800 \mathrm{mV}_{\mathrm{SCE}}$, and Figure 4 shows $C_{\mathrm{H} \text {-total }} \sim$ $1.2 C_{\mathrm{H} \text {-Diff, }}$ which is typical of $\mathrm{Ni}$-based superalloys. ${ }^{[29]}$ Assuming that Eq. [12] is relevant for Monel K-500, with $\varepsilon_{\mathrm{O}}=0.004$, this decrease in $C_{\mathrm{H} \text {-total }}$ results in increased $\varepsilon_{\mathrm{f}}^{\mathrm{H}} / \varepsilon_{\mathrm{O}}$ from 7.7 to 16.7. From Eq. [11], these changes in $\varepsilon_{\mathrm{f}}^{\mathrm{H}} / \varepsilon_{\mathrm{O}}$ yield $K_{\mathrm{THa}} / K_{\mathrm{THi}}$ of 2.8 at $-1100 \mathrm{mV}_{\mathrm{SCE}}, 7.6$ at $-800 \mathrm{mV}_{\mathrm{SCE}}$, and 650 or higher for $E_{\mathrm{A}}$ of $-760 \mathrm{mV}_{\mathrm{SCE}}$ and above. The trend predicted by this analysis is consistent with the HEAC loading format effect for Monel K-500. However, for this model to precisely fit with the HEAC experiments, the predicted $K_{\mathrm{THa}} / K_{\mathrm{THi}}$ at $-1100 \mathrm{mV}_{\mathrm{SCE}}$ should be 1 , rather than 2.8. Two issues preclude quantitative determination of $K_{\mathrm{THa}} / \mathrm{K}_{\text {thi }}$ vs $C_{\mathrm{H} \text {-total }}$. First, the relevance of Eq. [12] to Monel K-500 is not verified and a modest change in $\varepsilon_{\mathrm{f}}^{\mathrm{H}} / \varepsilon_{\mathrm{O}}$ 
strongly impacts $K_{\mathrm{THa}} / K_{\mathrm{THi}}$. Second, $A^{\prime}$ and $B$ in Eq. [11] are approximate for a work hardening alloy such as Monel K-500. The $K_{\mathrm{THa}} / K_{\mathrm{THi}}$ should decrease due to work hardening, compared to the Eq. [11] prediction. ${ }^{[49,101]}$ Work is required to better quantify this crack tip mechanics analysis for $\mathrm{Ni}$ superalloys, as well as to establish the physical basis for the contributions of enhanced $\mathrm{H}$ uptake, trap generation, and local work hardening unique to concurrent plasticity and $\mathrm{H}$ accumulation.

The difference in the HEAC susceptibility of Monel $\mathrm{K}-500$, subjected to rising step and hold loading compared to continuous-rising $K$, is understood based on damage from interaction of crack tip plasticity and H. An experiment, which produces sequential plastic strain followed by $\mathrm{H}$ accumulation, is less potent in terms of producing HEAC compared to slow-concurrent accumulation of strain and $\mathrm{H}$. For RSL, $\mathrm{H}$ does not accumulate during the fast-rising- $K$ step when strain accumulates, and crack tip strain does not accumulate during the hold (other than by low-rate creep) when $\mathrm{H}$ accumulates. With nil-concurrent plastic strain and $\mathrm{H}$ accumulation at intermediate cathodic polarization, $C_{\mathrm{H} \sigma}$ is low and $\varepsilon_{\mathrm{f}}^{\mathrm{H}}$ is high; PRHIC does not occur at a measurable rate. In contrast modest TG HEAC occurs during concurrent crack tip plastic strain and $\mathrm{H}$ accumulation characteristic of continuous-rising $K$ loading. For substantial cathodic polarization, crack tip $\mathrm{H}$ concentration is high and $\varepsilon_{f}^{\mathrm{H}}$ is low to favor HEAC, which occurs similarly for concurrent (slow-rising $K$ ) as well as sequential (RSL) crack tip plasticity and $\mathrm{H}$ accumulation.

Stress corrosion cracking in a Monel K-500 component depends on the interaction of loading protocol and level of cathodic polarization. Slow-rising $K$ with precisioncontinuous detection of crack growth provides $K_{\mathrm{TH}}$ and $\mathrm{d} a / \mathrm{d} t$ which are accurate to conservative for a given cathodic polarization. If a component is quasi-statically loaded such that plasticity accumulation is low during $\mathrm{H}$ uptake, or vice versa, then HEAC growth may be less than that projected based on the rising $K$ experiment. This difference is important at intermediate levels of cathodic polarization where crack tip $\mathrm{H}$ concentration is low to moderate. The present results show that significant HEAC is expected for aged Monel K-500 components stressed under slow-rising load at potentials in the range of $-800 \mathrm{mV}_{\mathrm{SCE}}<E_{\mathrm{A}}<-750 \mathrm{mV}_{\mathrm{SCE}}$. However, this "critical potential" regime is likely lower (more cathodic) for a statically loaded component such as a torqued fastener. This expectation should be compared to detailed analysis of the level of cathodic polarization for a crack location in a bare or painted Monel component coupled with zinc.

\section{CONCLUSIONS}

- The slow-rising stress intensity method, with dcPD monitoring of a small crack, provides a quantitativeaccelerated characterization of environmental cracking when enhanced to account for crack surface electrical contact, crack tip plasticity, and small-specimen ligament plasticity through $J$-integral analysis.

- Aged Monel K-500 is susceptible to severe IG HEAC in $\mathrm{NaCl}$ solution when cathodically polarized at $-800 \mathrm{mV}_{\mathrm{SCE}}$ and lower, concurrent with slow-rising stress intensity. Cracking is eliminated by cathodic polarization in the range of $-750 \mathrm{mV}_{\mathrm{SCE}}$ and above.

- Occluded crack tip diffusible $\mathrm{H}$ concentration rises with increasing cathodic polarization from -750 to $-1100 \mathrm{mV}_{\mathrm{SCE}}$, quantified for aged Monel K-500 by: (a) effective $\mathrm{H}$ solubility measured $v s \mathrm{H}$ overpotential on a planar electrode, and (b) measured-local crevice potential and $\mathrm{pH}$ geometrically scaled to a crack tip. Crack tip $\mathrm{H}$ concentration falls to near-0 wppm for bold-surface potentials above $-765 \mathrm{mV}_{\mathrm{SCE}}$.

- Experimentally measured and predicted dependencies of $K_{\mathrm{TH}}$ and $\mathrm{d} a / \mathrm{d} t_{\mathrm{II}}$ on crack tip diffusible $\mathrm{H}$ concentration (and applied cathodic potential) are in excellent agreement, validating these $\mathrm{H}$ decohesionbased models including dislocation-shielded high crack tip stress and a $1-\mu \mathrm{m}$ scale crack tip process zone. A single experimentally calibrated parameter is required for each model.

- Cathodic polarization, more negative than $-765 \mathrm{mV}_{\mathrm{SCE}}$, is required to cause HEAC in Monel K-500 for rising $K$ loading. The $\mathrm{H}$ concentration dependent term in the diffusion model for $\mathrm{d} a / \mathrm{d} t_{\mathrm{II}}$ explains a 5 to 10 order of magnitude increase in HEAC growth rate, over a narrow range of increasingly cathodic potential.

- HEAC in Monel K-500 is exacerbated by slow-rising $K$, which favors concurrent $\mathrm{H}$ exposure and crack tip strain accumulation compared to quasi-static loading. This loading protocol effect is increasingly important for moderate to low $\mathrm{H}$ uptake and increasing alloy fracture strain.

- The critical potential is likely more cathodic than $-800 \mathrm{mV}_{\mathrm{SCE}}$ for quasi-static loading and/or increasing alloy resistance to HEAC; depending on the $\mathrm{H}$ uptake relationship plus key parameters in the models for $K_{\mathrm{TH}}, \mathrm{d} a / \mathrm{d} t_{\mathrm{II}}$, and plasticity-based HEAC.

- When HEAC does not occur due to low H uptake, aged Monel K-500 may be susceptible to slow-rate TG cracking, perhaps creep crack growth.

\section{ACKNOWLEDGMENTS}

This research was sponsored by ONR Grants N0001406-1-0366 and N00014-10-1-0552 with Dr. Airan Perez as Scientific Officer. Fracture mechanics experiments were conducted by Mr. Yongwon Lee and Mr. Justin Dolph at the University of Virginia, Mr. J. Keith Donald at Fracture Technology Associates, and Dr. Matthew A. Adler at Westmoreland Mechanical Testing and Research. These contributions are acknowledged. 


\section{REFERENCES}

1. K.D. Efird: Mater. Perform., 1985, vol. 24, pp. 37-40.

2. L.H. Wolfe and M.W. Joosten: SPE Prod. Eng., 1988, vol. 3, pp. 382-86.

3. L.H. Wolfe and C.C. Burnette: Document 20294-MS, Society of Petroleum Engineers, 1990. (http://www.onepetro.org/mslib servlet/onepetropreview?id $=00020294$ ).

4. M.W. Joosten and L.H. Wolfe, Offshore Technology Conference Paper No. 5553-MS, April, 1987.

5. L.H. Wolfe, C.C. Burnette, and M.W. Joosten: Corrosion 93, Paper No. 288, NACE International, Houston, TX, 1993.

6. G.A. Scott: 17th Offshore Technology Conference, Paper No. OTC 5050, Houston, TX, 1985.

7. R.E. Butler: Engineering with Copper-Nickel Alloys, Metals Society, London, 1988, pp. 79-84.

8. L.H. Wolfe, C.C. Burnette, and M.W. Joosten: Mater. Perform. July, 1993, pp. 14-21.

9. C.A. Clark, S. Driscoll, and P. Guha: Br. Corros. J., 1997, vol. 27, pp. 157-60.

10. J.R. Scully and M.G. Vassilaros: The Hydrogen Embrittlement Susceptibility of Monel Alloy K-500, Report DTNSRDC/SME-8469, David Taylor Naval Ship Research and Development Center, Bethesda, MD, 1984.

11. R. Bayles, T. Lemieux, F. Martin, D. Lysogorski, T. Newbauer, W. Hyland, B. Green, E. Hogan, T. Longazel and P. Stencel: Naval Surface Treatment Center MR2010 Proceedings Presentation, 2010. (http://www.nstcenter.com/docs/PDFs/MR2010/Thurs1-Presentations/10-Bayles.PDF).

12. H.R. Copson and C.F. Cheng: Corrosion, 1956, vol. 12, pp. 647 53.

13. R.P. Gangloff: in Comprehensive Structural Integrity, I. Milne, R.O. Ritchie, and B. Karihaloo, eds., Elsevier, New York, NY, vol. 6, pp. 31-101, 2003.

14. J.A. Lillard: Ph.D. Dissertation, University of Virginia, Charlottesville, VA, 1998.

15. R.B. Rebak: in Environment Induced Cracking of Materials (EICM-2), S.A. Shipilov, R.H. Jones, J.-M Olive, and R.B. Rebak, eds., Elsevier, Oxford, pp. 435-46, 2007.

16. R.H. Jones and S.M. Bruemmer: in Environment Induced Cracking of Metals, R.P. Gangloff and M.B. Ives, eds., NACE, Houston, TX, pp. 287-310, 1990.

17. M.H. Kamdar: Second International Congress on Hydrogen in Metals, P. Azou, ed., Paper No. 3D10, Pergamon Press, Oxford, pp. 1-11, 1977.

18. D.H. Lassila and H.K. Birnbaum: Acta Metall., 1987, vol. 35, pp. 1815-22.

19. D.H. Lassila and H.K. Birnbaum: Acta Metall., 1988, vol. 36 , pp. 2821-25.

20. R. Otsuka, T. Maruno, and H. Tsuji: International Congress on Metallic Corrosion, National Research Council, Canada, 1984, vol. 2, pp. 270-77.

21. N.R. Moody, S.L. Robinson, and W.M. Garrison, Jr: Res. Mech., 1990, vol. 30, pp. 143-206.

22. D.M. Symons: Eng. Fract. Mech., 2001, vol. 68, pp. 751-71.

23. J.L. Mihelich and A.R. Troiano: Nature, 1963, vol. 197, pp. 996 97.

24. J.A. Harris, R.C. Scarberry, and C.D. Stephens: Corrosion, 1972 , vol. 28, pp. 57-62.

25. D.M. Aylor: Proceedings of the 1992 Tri-Service Corrosion Conference, M. Levy, ed., AMPTIAC Document No. AMO26091, 1992.

26. C.E. Price and R.S. Fredell: Metall. Trans. A, 1986, vol. 17A, pp. 889-98

27. A.W. Funkenbush, L.A. Heldt, and D.F. Stein: Metall. Trans. A, 1982, vol. 13A, pp. 611-18.

28. L. Raymond: Fracture and Stress Corrosion Cracking Resistance of C465, BioDur 108, SpT 13-8, K-Monel 500, and Zeron 100 Report \#CTC'071024, L. Raymond and Associates, Newport Beach, CA, 2008.

29. J. Ai, H. Ha, R.P. Gangloff, and J.R. Scully: Acta Mater., 2013, vol. 61, pp. 3186-99.

30. M.G. Vassilaros, R.L. Juers, M.E. Natishan, and A.K. Vasudevan: in Slow Strain Rate Testing for Evaluation of Environmentally Induced Cracking Research and Engineering Applications, ASTM STP 1210, R.D. Kane, ed., ASTM International, West Conshohocken, PA, pp. 123-33, 1993 .
31. M.G. Koul and P. S. LeGrand: Corrosion 2011, Paper No. 11296 , NACE International, Houston, TX, 2011.

32. M.A. Natishan and W.C. Porr, Jr.: in Structural Integrity of Fasteners, ASTM STP 1236, P.M. Toor, ed., ASTM International, West Conshohocken, PA, 1995, pp. 81-92.

33. S. Bechtle, M. Kumar, B.P. Somerday, M.E. Launey, and R.O. Ritchie: Acta Mater., 2009, vol. 57, pp. 4148-57.

34. S. Lynch: in Gaseous Hydrogen Embrittlement of Materials in Energy Technologies, R.P. Gangloff and B.P. Somerday, eds., Woodhead, Cambridge, 2012, vol. 1, pp. 274-346.

35. Y.D. Park, D.L. Olson, A. Landau, and M. Pinkas: Corrosion, 2006, vol. 62, pp. 395-402.

36. T. Boniszewski and G.C. Smith: Acta Metall., 1963, vol. 11, pp. 165-78.

37. M.L. Wayman and G.C. Smith: Acta Metall., 1971, vol. 19, pp. 227-31

38. M.L. Martin, B.P. Somerday, R.O. Ritchie, P. Sofronis, and I.M. Robertson: Acta Mater., 2012, vol. 60, pp. 2739-45.

39. Z. Guo, M. Zhao, C. Li, S. Chen, and L. Rong: Mater. Sci. Eng. $A$, 2012, vol. 555, pp. 77-84.

40. Y. Fukai: J. Alloys Compd., 2003, vols. 356-7, pp. 263-69.

41. W.W. Gerberich: in Gaseous Hydrogen Embrittlement of Materials in Energy Technologies, R.P. Gangloff and B.P. Somerday, eds., Woodhead, Cambridge, 2012, vol. 1, pp. 209-46.

42. Y. Lee and R.P. Gangloff: Metall. Mater. Trans. A, 2007, vol. 38A, pp. 2174-90

43. R.P. Gangloff: in Hydrogen Effects on Materials, B.P. Somerday, P. Sofronis, and R.H. Jones, eds., ASM International, Materials Park, OH, 2009, pp. 1-21.

44. W.W. Gerberich, R.A. Oriani, M.-J. Lii, X. Chen, and T. Foecke: Philos. Mag. A, 1991, vol. 62, pp. 363-76.

45. R.P. Gangloff: in Hydrogen Effects on Material Behavior and Corrosion Deformation Interactions, N.R. Moody, A.W. Thompson, R.E. Ricker, G.S. Was, and R.H. Jones, eds., The Minerals, Metals \& Materials Society, Warrendale, PA, 2003, pp. 477-97.

46. M.M. Hall, Jr. and D.M. Symons: in Chemistry and Electrochemistry of Stress Corrosion Cracking, R.H. Jones, ed., The Minerals, Metals \& Materials Society, Warrendale, PA, 2001, pp. 447-66.

47. U. Komaragiri, S.R. Agnew, R.P. Gangloff, and M.R. Begley: J. Mech. Phys. Solids, 2008, vol. 56, pp. 3527-40.

48. C.D.S. Tuck, Z. Xianghua, and D.E.J. Talbot: Br. Corros. J., 1994, vol. 29, pp. 70-74.

49. K.A. Nibur, B.P. Somerday, C. San Marchi, J.W. Foulk III, M. Dadfarnia, and P. Sofronis: Metall. Mater. Trans. A, 2013, vol. 44A, pp. 248-69.

50. J.P. Hirth: Metall. Trans. A, 1980, vol. 11A, pp. 861-90.

51. T.-Y. Zhang and J.E. Hack: Metall. Mater. Trans. A, 1999, vol. $30 \mathrm{~A}$, pp. $155-59$.

52. M. Dadfarnia, P. Sofronis, B.P. Somerday, D.K. Balch, P. Schembri, and R. Melcher: Eng. Fract. Mech., 2011, vol. 78, pp. 2429-38.

53. A. Taha and P. Sofronis: Eng. Fract. Mech., 2001, vol. 68, pp. 803-37.

54. B.A. Kehler and J.R. Scully: Corrosion, 2008, vol. 64, pp. 465-77.

55. J. Waldman, R.P. Gangloff, and W.E. Garrison: Final Report, STTR Topic No. N08-T010 (Phase II), Navmar Applied Sciences Corporation, Warminster, PA, 2011.

56. R.A. Mayville, R.J. Warren, and P.D. Hilton: Trans. ASME, 1987, vol. 109, pp. 188-93.

57. J. Alvarez and F. Gutierrez-Solana: Nucl. Eng. Des., 1999, vol. 188, pp. 185-202.

58. W. Dietzel, A. Atrens, and A. Barnoush: in Gaseous Hydrogen Embrittlement of Materials in Energy Technologies, R.P. Gangloff and B.P. Somerday, eds., Woodhead, Cambridge, 2012, vol. 1, pp. 237-73.

59. G.K. Dey and P. Mukhopadhyay: Mater. Sci. Eng., 1986, vol. 84, pp. 177-89.

60. T.L. Anderson: Fracture Mechanics, 3rd edn, Taylor \& Francis, Boca Raton, LA, 2005, pp. 121-23, 398-400, 445-46.

61. R.P. Gangloff, D.C. Slavik, R.S. Piascik and R.H. Van Stone: in Small Crack Test Methods, ASTM STP 1149, J.M. Larsen and J.E. Allison, eds., ASTM International, West Conshohocken, PA, 1992, pp. 116-68. 
62. J.K. Donald and J. Ruschau: Fatigue Crack Measurement: Techniques and Applications, EMAS, West Midlands, 1991, pp. 11-38.

63. H.H. Johnson: Mater. Res. Stand., 1965, vol. 5, pp. 442-45.

64. H. Tada, P.C. Paris, and G.R. Irwin: The Stress Analysis of Cracks Handbook, Paris Productions Incorporated, St. Louis, MO, 1985, pp. 2.10-2.12.

65. V. Kumar, M.D. German, and C.F. Shih: EPRI Final Report NP-1931, Electric Power Research Institute, Palo Alto, CA, 1981.

66. S.A. English and N.K. Arakere: Int. J. Plast., 2011, vol. 27, pp. 920-39.

67. S. Cravero and C. Ruggieri: Eng. Fract. Mech., 2007, vol. 74, pp. 2735-57.

68. A. Turnbull and J.G.N. Thomas: J. Electrochem. Soc., 1982, vol. 129 , pp. 1412-22.

69. J.S. Lee, M.L. Reed, and R.G. Kelly: J. Electrochem. Soc., 2004, vol. 151, pp. B423-B433.

70. Y. Xu and H.W. Pickering: J. Electrochem. Soc., 1993, vol. 140, pp. 658-68.

71. A.W. Hassel, K. Fushimi, and M. Seo: Electrochem. Commun., 1999, vol. 1, pp. 180-83.

72. R.P. Gangloff: Department of Defense 2013 Corrosion Conference, NACE International, Houston, TX, 2013.

73. R. Bayles: Private Communication, Naval Research Laboratory, Washington, DC, 2012.

74. C.E. Price and G.W. Henderson: Fatigue Fract. Eng. Mater. Struct., 1988, vol. 11, pp. 493-500.

75. B.P. Somerday, L.M. Young, and R.P. Gangloff: Fatigue Fract. Eng. Mater. Struct., 2000, vol. 23, pp. 39-58.

76. R.A. Ainsworth: Eng. Fract. Mech., 1984, vol. 19, pp. 633-42.

77. K.I. Azzabi, A.R. Luxmoore, and M.M.K. Lee: Int. J. Fract. 1991, vol. 63, pp. 75-87.

78. X.-K. Zhu and J.A. Joyce: Eng. Fract. Mech., 2012, vol. 85, pp. $1-46$.

79. C.F. Shih and M.D. German: Int. J. Fract., 1981, vol. 17, pp. 27 43.

80. C.F. Shih: Int. J. Fract., 1985, vol. 29, pp. 73-84.

81. G.Y. Katz, N. Tymiak, and W.W. Gerberich: Eng. Fract. Mech., 2001, vol. 68, pp. 619-46.

82. W.W. Gerberich, P.G. Marsh, and J.W. Hoehn: in Hydrogen Effects in Materials, A.W. Thompson and N.R. Moody, eds., TMS-AIME, Warrendale, PA, 1996, pp. 539-53.
83. R.A. Oriani: Berichte Bunsen Gesellschaft fur Physik Chemistry, 1972, vol. 76, pp. 848-57.

84. R.A. Oriani and P.H. Josephic: Acta Metall., 1974, vol. 22, pp. 1065-74.

85. R.A. Oriani: Corrosion, 1987, vol. 43, pp. 390-97.

86. J.R. Rice and R. Thomson: Philos. Mag., 1974, vol. 29, pp. 7397.

87. M.R. Begley, J.A. Begley, and C.M. Landis: in Gaseous Hydrogen Embrittlement of Materials in Energy Technologies, R.P. Gangloff and B.P. Somerday, eds., Woodhead, Cambridge, vol. 1, 2012, pp. 286-325.

88. A. Nagao, C.D. Smith, M. Dadfarnia, P. Sofronis, and I.M. Robertson: Acta Mater., 2012, vol. 60, pp. 5182-89.

89. M.L. Martin, I.M. Robertson, and P. Sofronis: Acta Mater., 2011, vol. 59, pp. 3680-87.

90. S. Wang, M.L. Martin, P. Sofronis, S. Ohnuki, N. Hashimoto, and I.M. Robertson: Acta Mater., 2014, vol. 69, pp. 275-82.

91. J.R. Scully and P.J. Moran: J. Electrochem. Soc., 1988, vol. 135, pp. $1337-48$.

92. C.J. McMahon, Jr: Eng. Fract. Mech., 2001, vol. 68, pp. 773-88.

93. Y. Takeda and C.J. McMahon, Jr: Metall. Trans. A, 1981, vol. 12A, pp. 1255-66.

94. I.M. Robertson, M.L. Martin, and J.A. Fenske: in Gaseous Hydrogen Embrittlement of Materials in Energy Technologies, R.P. Gangloff and B.P. Somerday, eds., Woodhead, Cambridge, 2012, vol. 1, pp. 166-206.

95. D. Delafosse: in Gaseous Hydrogen Embrittlement of Materials in Energy Technologies, R.P. Gangloff and B.P. Somerday, eds., Woodhead, Cambridge, 2012, vol. 1, pp. 247-85.

96. J.E. Angelo, N.R. Moody, and M.I. Baskes: Model. Simul. Mater. Sci. Eng., 1997, vol. 5, pp. 651-52.

97. D.M. Symons, G.A. Young, and J.R. Scully: Metall. Mater. Trans. A, 2001, vol. 32A, pp. 369-77.

98. Y. Shen and P.G. Shewmon: Metall. Trans. A, 1991, vol. 22A, pp. 1857-64.

99. P.G. Shewmon, Y.L. Shen, C.H. Shen, and M. Meshii: Acta Metall., 1989, vol. 37, pp. 1913-21.

100. N.R. Moody, R.E. Stoltz, and M.W. Perra: Metall. Trans. A, 1987, vol. 18A, pp. 1469-82.

101. R.O. Ritchie and A.W. Thompson: Metall. Trans. A, 1985, vol. 16A, pp. 233-48.

102. http://www.specialmetals.com/products/monelalloyk500.php. 